Check for updates

Cite this: RSC Adv., 2017, 7, 44843

Received 4th May 2017

Accepted 7th September 2017

DOI: $10.1039 / c 7 r a 05051 \mathrm{~h}$

rsc.li/rsc-advances

\section{The application of a UHPLC system to study the formation of various chemical species by compounds undergoing efficient self-aggregation and to determine the homodimerization constants $\left(K_{\mathrm{DM}}\right)$ with values in the high range of $10^{6}-10^{10}$ $M^{-1} \uparrow$}

\begin{abstract}
Magdalena Hetmańska*a and Andrzej Maciejewski (iD *ab
This work demonstrates a new concept for the use of UHPLC methodology for identification of the species formed by a self-aggregating compound depending on its concentration and solvent used, as well as to determine very large homodimerization constants $\left(K_{\mathrm{DM}}=10^{6}-10^{10} \mathrm{M}^{-1}\right)$. It is impossible to obtain such data with traditional UV-VIS and NMR measurements in compounds that undergo easy self-aggregation when their $K_{\mathrm{DM}}$ values are very large $\left(\geq 10^{7} \mathrm{M}^{-1}\right)$. The application of the UHPLC method in tandem with a UV-VIS photodiode spectrophotometer as a detector, as well as an emission detector allowed us to perform measurements at extremely low dye concentrations (down to $10^{-8} \mathrm{M}$ in the absorption measurement and down to $10^{-10} \mathrm{M}$ in the fluorescence measurement). Using the well-known probe 7-aminocoumarin (C120) as a model system, we separated the monomer (M) and dimer (DM) species, and determined their concentrations and individual absorption spectra. The position of the long wavelength band in the monomer absorption spectrum agreed very well with theoretically calculated values of vertical excitation energy to the $\mathrm{S}_{1}$ state of the $\mathrm{C} 120$ monomer. To the best of our knowledge, this is the first report on the very efficient self-aggregation of $\mathrm{C} 120$ in solution, with $K_{\mathrm{DM}}=1.5 \times 10^{9} \mathrm{M}^{-1}$ in polar $\mathrm{ACN}$ and $K_{\mathrm{DM}}=9 \times 10^{9} \mathrm{M}^{-1}$ in more weakly interacting 1-chlorobutane (ChB).
\end{abstract}

\section{Introduction}

If the absorption spectra (AS) and emission spectra (ES) of a compound have a constant shape in the concentration range of $10^{-5}-10^{-7} \mathrm{M}$, then that the compound is assumed to exist as single molecules (monomers) in solution. However, many compounds, including bisimide dyes, ${ }^{\mathbf{1}}$ merocyanine dyes, ${ }^{\mathbf{1}}$ squaraine dyes, ${ }^{\mathbf{1}}$ ureido-benzoic acid, ${ }^{2,3}$ porphyrins, ${ }^{4,5}$ and phthalocyanines, ${ }^{\mathbf{4 , 6}}$ and others, ${ }^{\mathbf{1 - 3 , 7}}$ that show strong intermolecular interactions resulting from hydrogen bond formation, coordinate bonds, $\pi-\pi$ stacking, and dispersive interactions, tend to exist as dimeric or oligomeric species. For such compounds, the homodimerization constant, $K_{\mathrm{DM}}$, is expected to be very high, particularly in weakly interacting solvents, and

${ }^{a}$ Photochemistry and Spectroscopy Laboratory, Faculty of Chemistry, Adam Mickiewicz University in Poznań, Umultowska 89b, 61-614 Poznań, Poland. E-mail: iwonam@ amu.edu.pl; mkiszko@amu.edu.pl; Fax: +48 6182915 55; Tel: +48 618291589 ${ }^{b}$ Centre for Ultrafast Spectroscopy, Adam Mickiewicz University in Poznań, Umultowska 89, 61-614 Poznań, Poland

$\dagger$ Electronic supplementary information (ESI) available. See DOI: 10.1039/c7ra05051h the dimer species can be efficiently formed in the solution at concentrations as low as $10^{-6}$ M.1,4,6,7

Equilibrium constants $\left(K_{\mathrm{eq}}\right)$ for systems containing monomer-dimer, cis-trans isomers, enol-keto tautomers, etc., may be determined by NMR, UV-VIS, IR, emission spectroscopy, CD, etc., when the value of $K_{\mathrm{eq}}=1-10^{4},{ }^{8}$ with HPLC also being frequently employed for these determinations. ${ }^{8-10}$ HPLC may be used when the equilibrium is reached rapidly and when the time required to reach equilibrium is negligible compared to the time required to isolate the species. ${ }^{9}$ However, HPLC cannot determine the individual species within a system. During separation, the analyte behaves as a single compound, exhibiting properties that are a composite of the properties of all the individual analyte species coexisting in the separation system. Only one peak is displayed in the chromatogram. For compounds that produced highly stable species, the equilibrium is attained slowly in comparison with the duration of the separation experiment, resulting in the presence of several peaks in the chromatogram, each corresponding to an individual species. Each species may be separated and determined individually. Thus, the HPLC method can be applied for the determination of $K_{\mathrm{DM}}$ values for compounds which easily 
undergo self-aggregation, when the existing dimers are sufficiently stable., ${ }^{\mathbf{9} 10}$ For the determination of very high homodimerization constants $\left(K_{\mathrm{DM}}>10^{6} \mathrm{M}^{-1}\right)$, very low concentrations of analyte must be used, e.g., when $K_{\mathrm{DM}}=10^{8} \mathrm{M}^{-1}$, then $c=10^{-8}-10^{-6} \mathrm{M}$ should be used, so that the concentrations of monomer $(\mathrm{M})\left(c_{\mathrm{M}}\right)$ and dimer (DM) $\left(c_{\mathrm{DM}}\right)$ can undergo distinct changes, and the ratio $c_{\mathrm{DM}} / c_{\mathrm{M}}=1-10$. Only UV-VIS absorption spectroscopy (when $\varepsilon^{\max } \sim 10^{4} \mathrm{M}^{-1} \mathrm{~cm}^{-1}$ ) and emission spectroscopy (when quantum yield of fluorescence $\left(\Phi_{\mathrm{F}}\right)$ is sufficiently large $>10^{-2}$ ) permit measurements at such low concentrations. A very sensitive LC-MS method has enabled the identification of investigated compounds (as well as the formation of sufficiently stable species), but the determination of $K_{\mathrm{DM}}$ values has not been possible.

For many heterodimers with very strong noncovalent interactions between monomers from two different compounds (A, B), very high association (heterodimerization) constants $\left(K_{\text {ass }}\right)$, of the order $10^{6}-10^{12} \mathrm{M}^{-1}$, have been found by UV-VIS and fluorescence titration methods., ${ }^{\mathbf{1 , 2 , 4 , 5 , 7 , 1 1 , 1 2}}$ Unfortunately, these methods cannot be applied to determine homodimerization constants of self-aggregated species. One can expect that $K_{\mathrm{DM}}$ values of numerous compounds which easily undergo selfaggregation are very high, similar to the values of $K_{\text {ass }}{ }^{1-4,6,7,13-19}$ Unfortunately, there is no known experimental method for the determination of $K_{\mathrm{DM}}>10^{7} \mathrm{M}^{-1}$ for noncovalent homodimers. To determine the contents of $\mathbf{M}$ and DM species in a sample of known concentration, one must know the value of $K_{\mathrm{DM}}$.

Determination of very high $K_{\mathrm{DM}}$ values would allow us to identify the compounds and solvents with the best properties for the formation of systems of practical importance, including supramolecular polymers, ,13,14,20,21 aggregation-induced emission active materials, ${ }^{7,22}$ optical sensors based on dimermonomer equilibrium as near-infrared fluorescence sensors for proteins $^{23}$ to sense $\mathrm{pH}$ in a broad range ${ }^{24}$ and for nucleic acids determination. ${ }^{25}$ For the determination of $K_{\mathrm{DM}}$, the monomer, dimer, or larger species formed by the investigated compounds must be identified. NMR is an indispensable method for determining if a studied compound occurs as a monomer, a dimer or a mixture. ${ }^{1-3,26}$ A comparison of NMR spectra distinguishes between homodimers and heterodimers. ${ }^{1-3,26,27}$ However, to analyze a sample by NMR methodology, sample concentrations must be $\geq 10^{-4} \mathrm{M}$ and thus, NMR spectroscopy is not useful to determine $K_{\mathrm{DM}}>10^{6} \mathrm{M}^{-1}$.

Simple simulations (Table $\mathrm{S} 1 \dagger$ ) show that for the compounds whose $K_{\mathrm{DM}}$ values are in the range of $\leq 10^{4} \mathrm{M}^{-1}$, only monomers are present $\left(c_{\mathrm{M}} / c_{\mathrm{DM}}=100\right)$ in the solution, if the studies are carried out in the range of low concentrations $\left(\leq 10^{-6} \mathrm{M}\right)$. On the other hand, if $K_{\mathrm{DM}}=10^{6}-10^{7} \mathrm{M}^{-1}$, then in the concentration range of $10^{-6}-10^{-7} \mathrm{M}$, both monomers (M) and dimers (DM) are present (Table S1 $\dagger$ ). Thus, the AS and ES represent the combined spectra of $\mathrm{M}$ and DM. If the value of $K_{\mathrm{DM}} \geq 10^{8} \mathrm{M}^{-1}$, then even in the range of very low concentrations $\left(10^{-7}-10^{-8} \mathrm{M}\right)$, the concentration of dimer is greater than that of monomer (Table $\mathrm{S} 1 \dagger)$. For a compound with $K_{\mathrm{DM}} \geq 10^{7} \mathrm{M}^{-1}$ in the concentration range $\geq 10^{-6} \mathrm{M}$, the AS would represent mostly the absorption of the dimer and not that of the monomer, as commonly assumed. Therefore, the spectrophotometric determination of the AS of the monomer is not applicable to compounds with values of $K_{\mathrm{DM}}$ $\geq 10^{7} \mathrm{M}^{-1}$. To obtain the monomer at concentration 10 times greater than that of dimer, when $K_{\mathrm{DM}}=1 \times 10^{8} \mathrm{M}^{-1}$, the concentration of the investigated compound must be less than 1 $\times 10^{-9} \mathrm{M}$ (Table S1 $\dagger$ ). The AS for such low concentrations cannot be measured, even when the values of $\varepsilon^{\max }$ are very high $\left(\sim 10^{5} \mathrm{M}^{-1} \mathrm{~cm}^{-1}\right)$ and the cell path length is $10 \mathrm{~cm}$.

For compounds that undergo easy self-aggregation, it is difficult to establish which of the species are present and to determine their concentration, their AS and the $\varepsilon(\lambda)$ values. To obtain these data, it is necessary to determine the $K_{\mathrm{DM}}$ value. For the compounds whose monomer and dimer have similar AS and $\mathrm{ES}^{28-33}$ it is impossible to determine their concentrations (i.e., those of monomer and dimer) and thus their $K_{\mathrm{DM}}$ value by measurements of AS on a spectrophotometer and ES on a spectrofluorimeter.

In this work, we demonstrate that by using UHPLC in conjunction with a photodiode UV-VIS spectrophotometer (PDA) and an emission detector, it is possible to determine the species formed in the range of very low concentrations $\left(10^{-6}-10^{-8} \mathrm{M}\right)$ after their previous separation. This methodology opens the door to determining very high values of $K_{\mathrm{DM}}=10^{6}-10^{10} \mathrm{M}^{-1}$. The determination of such high $K_{\mathrm{DM}}$ values will permit the first ever determination of the type of species (only monomer, only dimer or both) of compounds undergoing efficient self-aggregation in a sample of known concentration.

Coupling the HPLC technique with photodiode UV-VIS spectrophotometers and emission detectors makes a very sensitive method. In an earlier work, we studied compounds with very weak emissions without interference from impurities by using an HPLC system..$^{34}$ We defined the main assets of using HPLC and UHPLC by studying three tautomers of gossypol ${ }^{34}$ and two complexes formed by benzopyrantione with water molecules. ${ }^{35}$ The HPLC method was successfully applied to the separation of monomers, dimers and larger aggregates. ${ }^{36-39}$ Size exclusionHPLC has been used to detect and characterize M, DM and higher aggregates of protein ${ }^{39}$ as well as to study M-DM equilibrium of gramicidin. ${ }^{36}$ Würthner at al. ${ }^{1}$ first separated conformationally stable atropo-diastereomers of perylene bisimides, derivatives with a high activation barrier $\left(E_{\mathrm{a}} \geq 97 \mathrm{~kJ} \mathrm{~mol}^{-1}\right)$ for racemization. In recent work on 1-butyl-3-methylimidazolium tetrafluoroborate, we showed for the first time that linking together the HPLC setup with a high performance PDA and emission detector enabled separation of the species formed by this ionic liquid from impurities present in the solution and independently measured the absorption and emission spectra and other spectral properties of the species and the impurities. ${ }^{\mathbf{4 0}}$

7-Aminocoumarins are the derivatives of 1,2-benzopyrone having amino groups at position 7 of the 1,2-benzopyrone moiety. They are often used as fluorescence probes, ${ }^{41-43}$ chemosensors, ${ }^{44}$ in biological and biomedical sciences, ${ }^{45,46}$ and in dye lasers. ${ }^{47}$ Coumarin-120 (7-amino-4-methyl-1,2-benzopyrone) (Scheme 1), abbreviated as $\mathrm{C} 120$, belongs to this group, having a simple $\mathrm{NH}_{2}$ group. The fluorescence quantum yields of this dye in solvents of moderate to higher polarities are very high $\Phi_{\mathrm{F}}$ $\geq 0.5$ (ref. 48 and 49) and the absorption and especially 


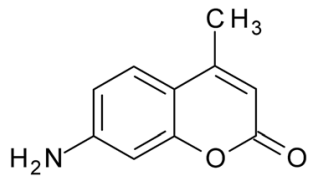

Scheme 1 Chemical structure of the coumarin-120 (C120) molecule.

emission maxima, as well as Stokes shifts, were found to be strongly dependent on polarity and hydrogen bonding ability of the solvent. Therefore, $\mathrm{C} 120$ has been widely used as a probe for studying solute-solvent interactions and solvatochromic properties of various systems and it has been the focus of intensive studies, both experimental ${ }^{48,49}$ and theoretical ${ }^{50}$ ones. C120 is also a well-known laboratory reagent, employed as a fluorogenic probe for detection of enzymatic activity. ${ }^{51}$ This dye has been used as a fluorescence probe to analyze glycoproteins, monosaccharides and $N$-linked oligosaccharides via chromatography. ${ }^{52} \mathrm{C} 120$ has also shown effective antitubercular, ${ }^{53}$ antibacterial and antifungal ${ }^{54}$ activities. It is known to be nontoxic to humans and animals.

Spectral and photophysical studies of C120 have usually been performed with dye solutions over the concentration range of $10^{-4}-10^{-5} \mathrm{M}^{41-43,48,49}$ It has always been assumed that within this concentration range, the dye exists in the solution as a monomer and/or possibly as the complex formed by the dye molecule and solvent molecules in hydrogen bonding solvents. However, the formation of stable dimers or even larger aggregates has been recently postulated for several derivatives of aminocoumarins in the concentration range of $c=10^{-4}$ $10^{-6} \mathrm{M}^{55-57}$ These properties made $\mathrm{C} 120$ a good candidate for our investigations using UHPLC in conjunction with a photodiode UV-VIS spectrophotometer and an emission detector (UHPLC-PDA-FL system) for identification of the type of species made by this compound in a wide range of concentrations $\left(c=10^{-5}-10^{-8} \mathrm{M}\right)$, and for determination of its $K_{\mathrm{DM}}$.

\section{Experimental section}

Coumarin 120 (C120), of purity $>99 \%$, (Applied Photophysics Ltd.) was used as received. Acetonitrile (ACN) (Sigma Aldrich, Chromasolv gradient grade for HPLC $\geq 99.9 \%$ ) and 1-chlorobutane (ChB) for HPLC (Sigma Aldrich) were used as an eluent and a solvent. The absorption spectra of C120 labeled as conventional were measured using a double beam spectrophotometer type V-650 (Jasco). The emission spectra of C120 labeled as conventional were measured using a Jobin Yvon-Spex Fluorolog3-22 spectrofluorimeter.

All chromatographic measurements were performed using a Waters Ultra-High Performance Liquid Chromatography (UHPLC) system with a Photodiode Array Detector (PDA) (flow cell path length of $2.5 \mathrm{~cm}$, volume: $1.25 \mu \mathrm{l}$ ) with linear working range for absorbance near $A=2$ and Acquity UPLC fluorescence detector (flow cell of $2 \mu \mathrm{l}$ volume). An Empower 2 chromatographic interface was used for data collection. The Kinetex Phenyl-Hexyl $150 \times 2.10 \mathrm{~mm}$ column (Phenomenex) packed with $1.7 \mu \mathrm{m}$ particles with pore size $100 \AA$ was used. Isocratic elution was carried out with acetonitrile (ACN) or 1-chlorobutane $(\mathrm{ChB})$ at the flow rate of $0.10,0.25,0.50$ or $1.0 \mathrm{ml} \mathrm{min}{ }^{-1}$. All measurements were carried out at ambient temperature. Isocratic elution mode with $\mathrm{ACN}$ or $\mathrm{ChB}$ was used and no buffer was added to the eluent. The Core-Shell Technology (a Kinetex type) columns used in this work are much more efficient than traditional fully porous sub- $2 \mu \mathrm{m}$ columns, yielding a remarkable chromatographic resolution, higher peak capacities, and a greater sensitivity because of very narrow chromatographic peaks, $\Delta t_{\mathrm{R}}{ }^{1 / 2}=1-3 \mathrm{~s}$ (absorption) and $\Delta t_{\mathrm{R}}{ }^{1 / 2}=3-4.5 \mathrm{~s}$ (emission). The use of the UHPLC method allowed a reliable determination of very low concentrations of the separated compound and species by at least one order of magnitude lower than those that could be determined with the HPLC method. All dye concentration data for the UHPLC method measurements are given for injected solutions.

Because it was necessary to work at very low concentrations of $\mathrm{C} 120\left(c_{\mathrm{C} 120}=10^{-6}-10^{-9} \mathrm{M}\right)$, we took special precautions to assure that our data were accurate and reliable. Within one measuring cycle, the measurements were carried out repeatedly with numerous injections. Only reproducible absorption chromatograms and absorption spectra as well as reproducible emission chromatograms were selected for analysis of results. It is worth noting that the signal-to-noise ratios $(\mathrm{S} / \mathrm{N})$ for the lowest investigated concentrations $\left(c_{\mathrm{C} 120}=1.9 \times 10^{-8} \mathrm{M}\right)$ were sufficiently high $(\mathrm{S} / \mathrm{N} \geq 3$ for the peak $\mathrm{B}$ and $\mathrm{S} / \mathrm{N} \sim 25$ for the peak A) when absorption chromatograms were obtained in the range of $\lambda=280-340 \mathrm{~nm}$. Since the measurement error was very small $\left(\Delta A= \pm 2 \times 10^{-5}\right)$, the value of $\mathrm{S} / \mathrm{N} \geq 3$ was reliable. The peaks A and B were also intensive in emission chromatograms, (particularly the peak A). For low C120 concentration $(1.9 \times$ $10^{-8} \mathrm{M}$ ), the $\mathrm{S} / \mathrm{N}$ ratio was greater than 500 for the peak $\mathrm{A}$ and $\mathrm{S} /$ $\mathrm{N} \sim 50$ for the peak B, provided that suitable $\lambda_{\mathrm{ex}}$ and $\lambda_{\mathrm{em}}$ were selected. Due to this, accurate measurements of emission chromatograms were possible even for concentrations of $10^{-9}-10^{-10} \mathrm{M}$.

To eliminate the effect of impurities in the solvent and the eluent as well the wavelength effect on the contribution from reflected and dispersed light, measurements were carried out for C120 samples in ACN and for ACN alone and also for C120 samples in $\mathrm{ChB}$ and for $\mathrm{ChB}$ alone. Absorption and emission chromatograms and AS originating solely from the dimer (DM) and the monomer (M) (see below) were obtained by subtracting experimental absorption and emission chromatograms and AS of the solvent (ACN and $\mathrm{ChB}$ ) from experimental absorption and emission chromatogram and AS of a sample (C120 in ACN and $\mathrm{C} 120$ in $\mathrm{ChB}$ ). For $c_{\mathrm{C} 120} \geq 10^{-6} \mathrm{M}$, absorption and emission of ACN and ChB alone was so small that they could be neglected.

\section{Results and discussion}

Absorption and emission spectra of $\mathrm{C} 120$ in the concentration range of $10^{-4}-10^{-6} \mathrm{M}$ (in ACN and other solvents) measured on UV-VIS spectrophotometers and on spectrofluorimeters, both by us and other authors, had the same shape. ${ }^{48,49}$ In low concentrations $\left(10^{-4}-10^{-6} \mathrm{M}\right)$ of $\mathrm{C} 120$ applied in these measurements, it was always assumed that the spectra originate 
from single molecules (monomers) of C120.48,49 To verify this assumption, measurements of absorption chromatograms and AS, as well as of emission chromatograms, for solutions of C120 in $\mathrm{ACN}$ in the concentration range of $10^{-5}-10^{-8} \mathrm{M}$ were performed using the UHPLC-PDA-FL system.

The application of this new generation UHPLC instrument and columns of core-shell type produced on absorption chromatograms very narrow peaks $\left(\Delta t_{\mathrm{R}}{ }^{1 / 2}=1.5-2 \mathrm{~s}\right)$ of separated species and allowed measuring very low absorbancies $\left(A=10^{-3}-10^{-4}\right)$ with a very small error $\left(\Delta A= \pm 2 \times 10^{-5}\right)$. Due to such instrumental parameters, the separation (at least a partial one) of species with very close retention times (differing by merely 1 second) is possible and measurements can be carried out in the spectral range of $\lambda=190-800 \mathrm{~nm}$ and at very low concentrations $\left(10^{-6}-10^{-8} \mathrm{M}\right)$. The complete separation of $\mathrm{M}$ (peak $\mathrm{B}$ ) from DM (peak A), obtained in the absorption chromatograms (Fig. 2, 5 and $\mathrm{S} 1 \dagger$ ), was also maintained in the emission chromatograms (Fig. 6, S2 and S3†), although it appeared to be slightly worse. It should be mentioned that due to installing the PDA detector first and placing the emission detector immediately after it, $t_{\mathrm{R}}^{\max }$ of $\mathrm{M}$ and $\mathrm{DM}$ peaks in the emission chromatograms are by 3-6 s longer depending on the eluent flow rate. Since the cell volume $(2 \mu \mathrm{l})$ in the emission detector was considerably higher than that $(1.25 \mu \mathrm{l})$ in the PDA detector and data acquisition in the emission detector is slower $(20-50 \mathrm{~Hz})$ than in the PDA detector $(80 \mathrm{~Hz})$, the peaks of $\mathrm{M}$ and DM in the emission chromatograms were about twice as wide as those in the absorption chromatograms.

\subsection{Species formed by $\mathrm{C} 120$ in $\mathrm{ACN}$}

3.1.1. Measurement in the concentration range $10^{-4}-10^{-5}$ M. The absorption chromatograms measured for C120 solutions in ACN at the concentration of $4.6 \times 10^{-5} \mathrm{M}$ show a single chromatographic peak of the same shape and position of the maximum, irrespective of the observation wavelength varying in the range 290-360 nm (Fig. 1).
Moreover, the position of the maximum and the shape of the long-wavelength band in the absorption spectrum determined for different retention times did not change and were the same as the absorption spectrum measured using an UV-VIS spectrophotometer for C120 solution $\left(c=10^{-4}-10^{-6} \mathrm{M}\right.$ ) in ACN (see Fig. $4 \mathrm{~b})$. The only peak present in the absorption chromatogram in the range $10^{-4}-10^{-5} \mathrm{M}$ (Fig. 1) can be ascribed to the monomer of the investigated compound, in compliance with the all previous interpretations. However, the $K_{\mathrm{DM}}$ value for the compounds easily undergoing self-aggregation can be large enough to expect that the above peak can originate from the dimer. Therefore, to determine whether the only peak present in the absorption chromatogram should be ascribed to the monomer or the dimer, we performed measurements in a wide enough range of very small concentrations of C120.

3.1.2. Measurements in the concentration range $10^{-6}-10^{-8}$ M. For the solutions of C120 in ACN at concentrations $10^{-6} \mathrm{M}$ and lower, the absorption chromatograms at slightly longer retention times showed an additional, less intense peak at the observation wavelength range of 300-330 nm (Fig. 2). The shape and position of the peaks were not dependent on the C120 concentration. Their intensities depended on the observation wavelength. The intensity of the first peak (referred to as A), with a maximum at the retention time of $t_{\mathrm{R}}^{\max }=1.29 \mathrm{~min}$ for the flow rate of $0.25 \mathrm{ml} \mathrm{min}{ }^{-1}$ (Fig. 2a) and the retention time of $t_{\mathrm{R}}^{\max }=0.64 \mathrm{~min}$ for the flow rate of $0.5 \mathrm{ml} \mathrm{min}^{-1}$ (Fig. 2b) was the highest for the observation wavelength of $340 \mathrm{~nm}$. The intensity of the second peak (referred to as B), with the maximum at the retention time of $t_{\mathrm{R}}^{\max }=1.48 \mathrm{~min}$ (Fig. 2a) and the retention time of $t_{\mathrm{R}}^{\max }=0.73 \mathrm{~min}$ at the faster flow rate (Fig. 2b), was the highest at 290-300 nm.

As in the case of higher dye concentrations, the absorption spectra, in particular the position of the maximum and the shape of the long-wavelength band determined for the retention times within the chromatographic peak A (Fig. 3a), corresponded to the absorption spectrum measured using a Jasco V-650 Spectrophotometer for the C120 solutions in ACN, a)

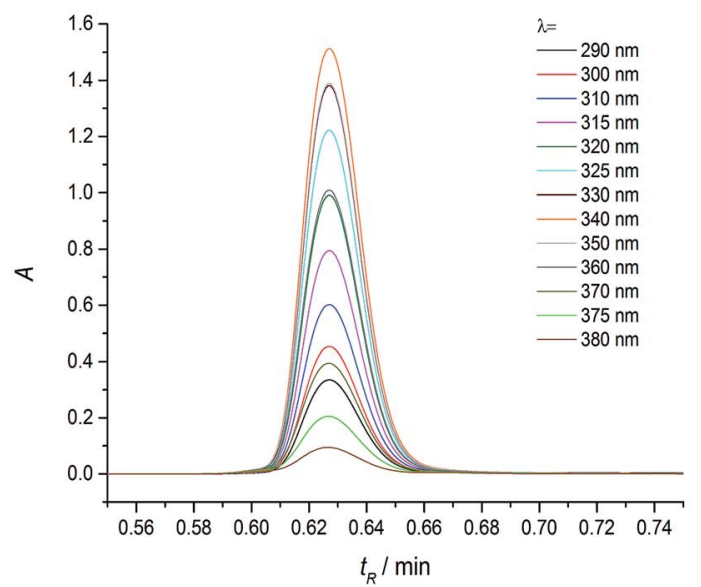

b)

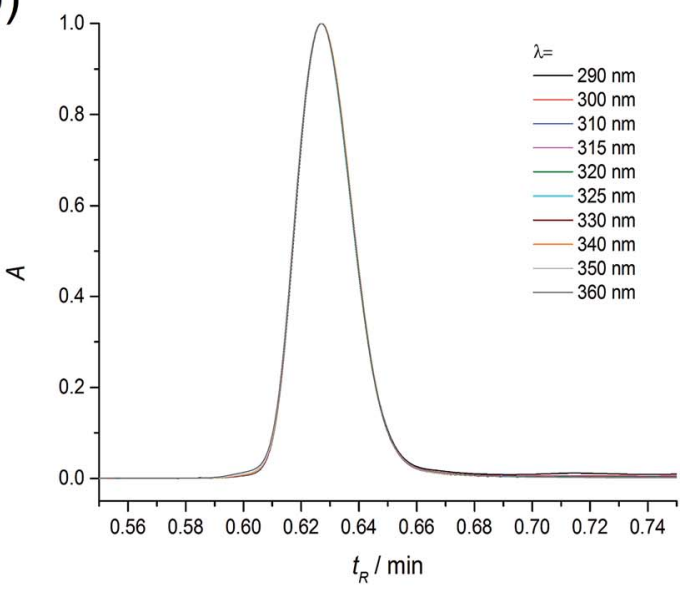

Fig. 1 Raw (a) and normalized (b) absorption chromatograms of coumarin-120 (C120) in ACN at the dye concentration of $4.6 \times 10^{-5} \mathrm{M}$, recorded over a wide range of detection wavelengths (the flow rate was $0.5 \mathrm{ml} \mathrm{min}{ }^{-1}$ ). 
a)

a)

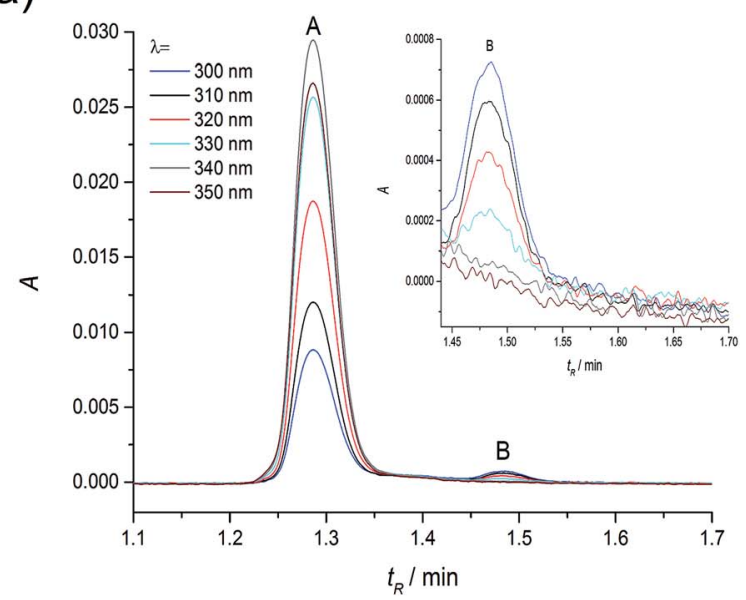

b)

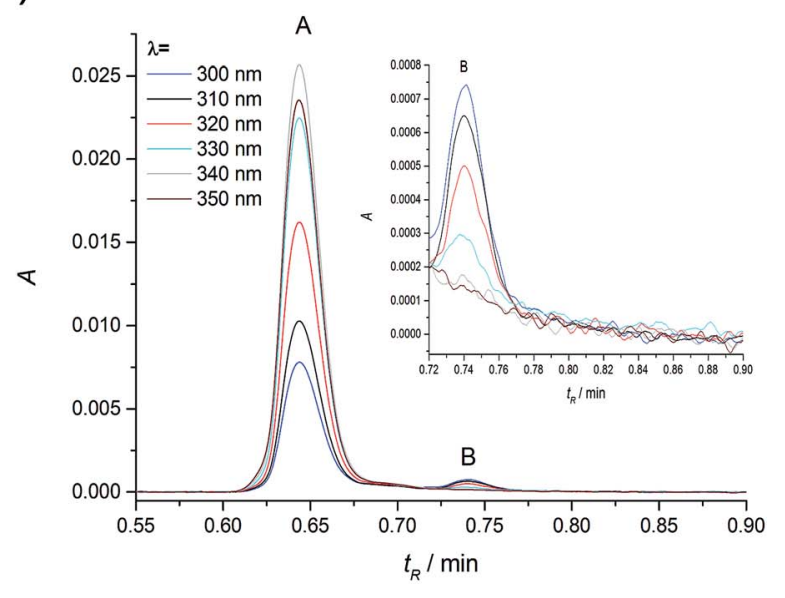

Fig. 2 Experimental absorption chromatograms of coumarin 120 (C120) in ACN at the dye concentration of $1.1 \times 10^{-6} \mathrm{M}$, recorded over a wide range of detection wavelengths. (a) Flow rate of $0.25 \mathrm{ml} \mathrm{min}{ }^{-1}$; (b) flow rate of $0.5 \mathrm{ml} \mathrm{min}$.

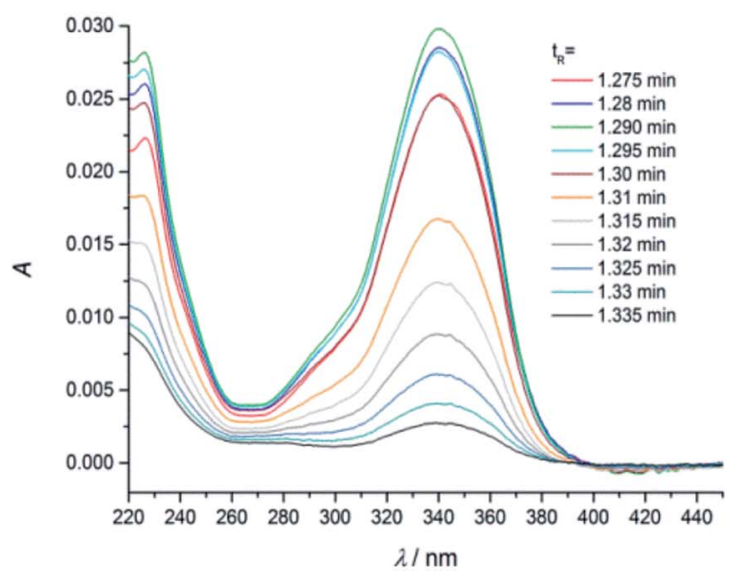

b)

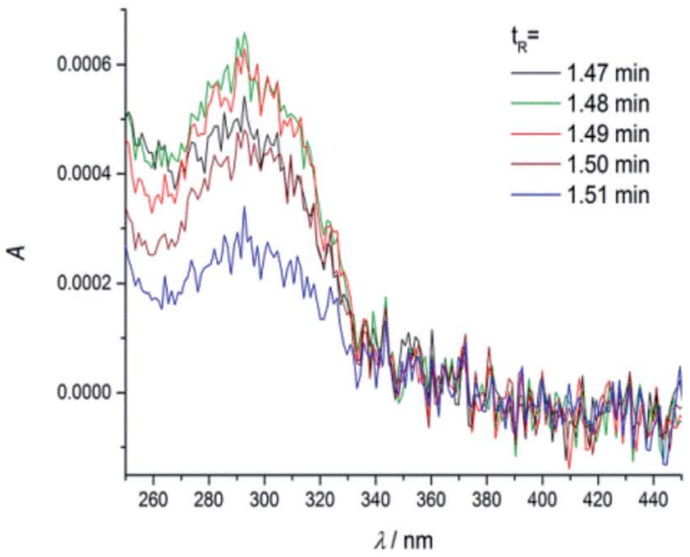

Fig. 3 Absorption spectra of coumarin-120 (C120) in ACN at the dye concentration of $1.1 \times 10^{-6} \mathrm{M}$, recorded (a) in the range of retention times 1.275-1.335 min (peak A) from Fig. $2 a$ and $b$ in the range of retention times $1.47-1.51$ min (peak $B$ ), from Fig. $2 a$, flow rate of 0.25 ml min ${ }^{-1}$.

(Fig. 4b). The absorption spectra recorded for different retention times from the peak B (Fig. 3b) were the same or similar, however, they were totally different from those within the chromatographic peak A. The long-wavelength bands in the AS, determined at the maximum of the peaks $\mathrm{A}$ and $\mathrm{B}$ and normalized to the same intensity, are presented in Fig. 4 . The maximum of the long-wavelength band $(\lambda \sim 295 \mathrm{~nm})$ in the absorption spectrum recorded at the peak B was clearly shifted towards shorter wavelengths relative to the corresponding band in the spectrum recorded at the peak $\mathrm{A}$ (the maximum at $340 \mathrm{~nm})$.

The presence of two peaks in the absorption chromatogram and clearly different AS within both peaks suggested the existence of at least two absorbing species in the C120 solutions.

The two peaks present in the chromatogram (Fig. 2) could originate from: (a) two monomers with considerably different concentrations,

(b) the monomer and an impurity present in it,

(c) the monomer and the dimer.

To distinguish among these possibilities, we conducted measurements over a wide range of concentrations. Since in the case of concentrations $\geq 10^{-5} \mathrm{M}$ only the peak A was observed (Fig. 1), we also carried out studies over the range from $1.1 \times 10^{-6}$ to $1.9 \times 10^{-8} \mathrm{M}$. Herein, we present the outcomes of studies with three concentrations that show marked changes in the ratio of $A^{\max }$ (peak B) $/ A^{\max }$ (peak A) and for the sample of the lowest concentration the above ratio was as high as possible. By evaluating the data in this way for C120 (particularly the interpretation of absorption chromatograms) our conclusions could be maximally reliable.

Measurements of absorption chromatograms by using a photodiode spectrophotometer and absorption spectra taken 
a)

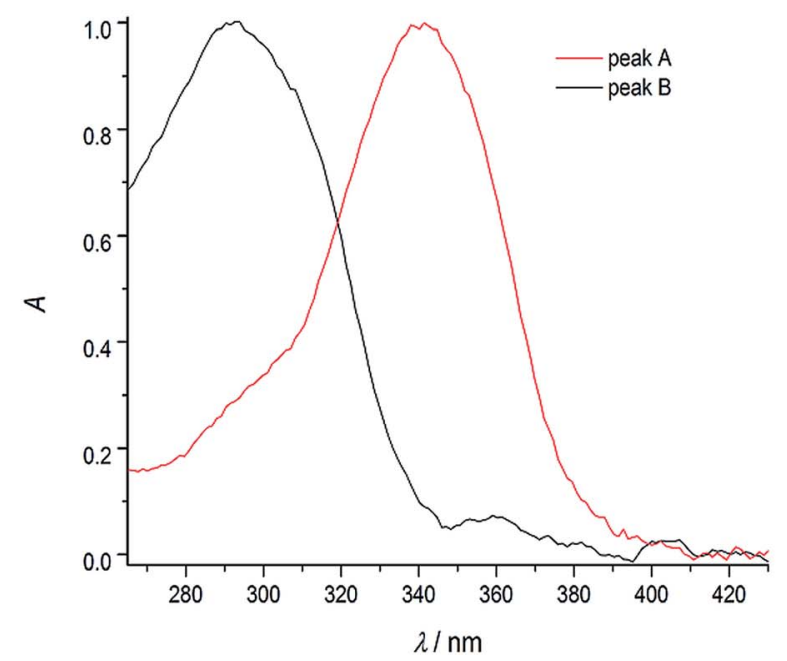

b)

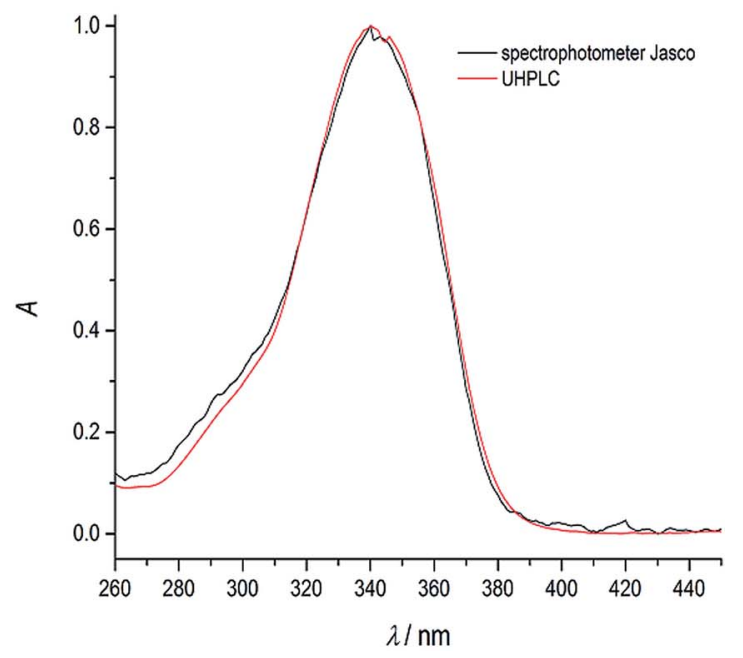

Fig. 4 (a) Normalized absorption spectra of coumarin-120 (C120) in ACN at the dye concentration of $1.1 \times 10^{-6} \mathrm{M}$, recorded at the maxima of chromatographic peaks A and B (see Fig. 2 and 3); (b) a comparison of normalized absorption spectra at the maximum of the peak A (a) and absorption spectrum measured using a Jasco V650 UV-VIS spectrophotometer at the dye concentration of $4.6 \times 10^{-7} \mathrm{M}$.

for chosen $t_{\mathrm{R}}$ values are single beam measurements. Studies carried out with samples having the lowest C120 concentrations $\left(c=10^{-7}-10^{-8} \mathrm{M}\right)$ inevitably entailed measuring very low values of absorbance $\left(A=10^{-3}-10^{-4}\right)$. Because we performed our studies under conditions that corrected for any experimental artifacts from the solvents (see Experimental procedures), we were able to obtain reliable absorption chromatograms, even at very small concentrations (Fig. S1†). Therefore, we were confident that the number of peaks in a chromatogram corresponded to the number of species formed by $\mathrm{C} 120$.

The presence of two peaks in all absorption chromatograms, characterized by identical profiles, as well as the same $t_{\mathrm{R}}^{\max }$ and $\Delta t_{\mathrm{R}}{ }^{1 / 2}$ (for the same flow rates) indicated that two species formed by $\mathrm{C} 120$ existed in the range of $c_{\mathrm{C} 120}=10^{-6}-10^{-8} \mathrm{M}$.

Results of measurements obtained in compliance with the procedures developed by us, described in the Experimental section are presented in Fig. 5. Shapes of peak A and peak B, determined across a wide range of wavelength, were very similar. Also the positions $\left(t_{\mathrm{R}}^{\max }\right)$ and widths of peaks were very similar in the entire range of $\mathrm{C} 120$ concentrations. Moreover, the absorption spectra recorded for different retention times in the range of each peak are similar (Fig. 3). The chromatographic peak A, observed in the chromatograms recorded for the whole range of C120 concentrations $\left(c_{\mathrm{C} 120}=1.1 \times 10^{-6}-1.9 \times 10^{-8} \mathrm{M}\right)$ was always characterized by a considerably higher intensity than the peak $\mathrm{B}$.

A comparison of peaks A and B in samples differing significantly in their concentrations (Table 1) indicated that absorbance of the peak A was reduced as the C120 concentration decreased. On the other hand, absorbance of the peak $B$ decreased much less. With the reduction in concentration from $1.1 \times 10^{-6} \mathrm{M}$ to $1.9 \times 10^{-8}$, absorbance of the peak A diminished $\sim 61$-fold, whereas that of the peak B decreased only $\sim 7$ fold. Thus, the peak A and the peak B could originate neither from two monomers of C120 nor from C120 monomer plus an impurity. Indeed, the absorbances of both peaks decreased as the concentration of C120 decreased, but to a different extent. The clear increase in the ratio of $A^{\lambda=300}$ (peak B)/ $A^{\lambda=340}$ (peak A) with the decrease in $\mathrm{C} 120$ concentration (Table 1) suggests that the peak A originates from the dimer formed by two molecules of $\mathrm{C} 120$, whereas the peak B arises from a single molecule of C120 (the monomer).

Two molecules of C120 can form two identical hydrogen bonds between each other, between the oxygen atom of the carbonyl group of one molecule and the $\mathrm{N}-\mathrm{H}$ bond of another molecule. Moreover, $\pi-\pi$ interactions, as well as electrostatic and dispersion interactions can substantially contribute to the dimer formation. There are no literature reports presenting results or discussing formation of a homodimer by C120 molecules. A very efficient formation of dimers with various structures have been recently calculated for 7-hydroxycoumarin $^{57}$ and the dimerization energy for the most stable dimer was very similar to that obtained by us for C120 (7-aminocoumarin). ${ }^{58}$

To confirm whether the peak $\mathrm{A}$ in the chromatograms originates from the dimer and peak B from the monomer (Fig. 2, 5 and $\mathrm{S} 1 \dagger$ ) we have calculated concentrations of the monomer $\left(c_{\mathrm{M}}\right)$ and dimer $\left(c_{\mathrm{DM}}\right)$ using the eqn (1):

$$
K_{\mathrm{DM}}=\left(c_{\mathrm{DM}}\right) /\left(c_{\mathrm{M}}\right)^{2}
$$

To directly benefit from the calculated $c_{\mathrm{M}}$ and $c_{\mathrm{DM}}$, the calculations were performed for samples with the same concentrations as those used in experiments on C120 in ACN, knowing that $c_{\mathrm{C} 120}=c_{\mathrm{M}}+2 c_{\mathrm{DM}}$.

Since the concentration of the monomer $c_{M}$ (peak $B$ ) is considerably lower than the dimer concentration $c_{\mathrm{DM}}$ (peak A), even for the lowest concentration $\left(c_{\mathrm{C} 120}=1.9 \times 10^{-8} \mathrm{M}\right)$ (Fig. 5d), the $K_{\mathrm{DM}}$ value for $\mathrm{C} 120$ in $\mathrm{ACN}$ must be very high. 

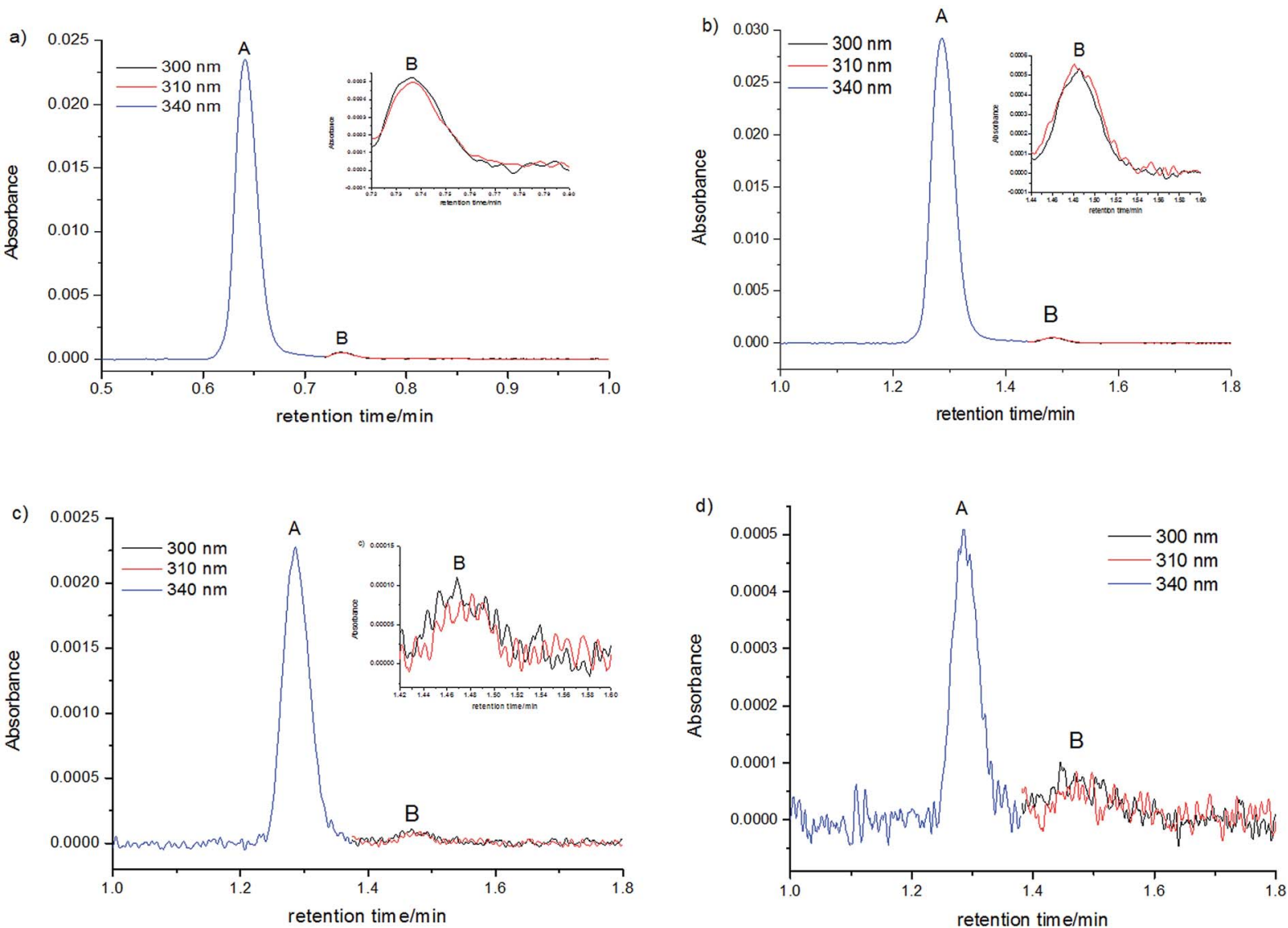

Fig. 5 Absorption chromatograms for C120 samples in ACN with concentrations of $1.1 \times 10^{-6} \mathrm{M}$ (a and b) $9.3 \times 10^{-8} \mathrm{M}$, (c) $1.9 \times 10^{-8} \mathrm{M}$, (d) measured for the dimer (see below). Peak $A,(\lambda=340 \mathrm{~nm}$ ) in the retention time range of 1.0-1.42 min $(b-d)$ and $0.5-0.72 \mathrm{~min}(a)$ and for the monomer (see below); peak $B,\left(\lambda=300,310 \mathrm{~nm}\right.$ ) in the retention time range of $1.42-1.8 \mathrm{~min}(\mathrm{~b}-\mathrm{d})$ and $0.72-1.0 \mathrm{~min}(\mathrm{a}) ;(\mathrm{a})$ flow rate $0.5 \mathrm{ml} \mathrm{min}^{-1}$,

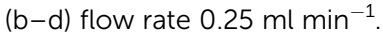

Table 1 The effect of $\mathrm{C} 120$ concentration on the mean absorbance at the dimer peak maximum (the peak $\mathrm{A}, \lambda=340 \mathrm{~nm}$ ) and the monomer peak maximum (the peak $B, \lambda=300 \mathrm{~nm}$ ) in absorption chromatograms (Fig. 5), and on the ratio of the mean absorbance $\left(A^{\lambda=300} / A^{\lambda=340}\right.$ ) and on the ratio of the mean concentration of $M$ and $D M, c_{M} / c_{D M}$

\begin{tabular}{lcclcccc}
\hline$c_{\mathrm{C} 120}[\mathrm{M}]$ & $c_{\mathrm{C} 120(\mathrm{rel})}$ & $N$ & $A^{\lambda=340 a}$ & $A_{\text {(rel) }}^{\lambda=340 a}$ & $A^{\lambda=300 b}$ & $A_{(\mathrm{rel})}^{\lambda=300 b}$ & $A^{\lambda=300} / A^{\lambda=340}$ \\
\hline $1.1 \times 10^{-6}$ & 57.9 & 3 & 0.0293 & 61.0 & 0.00053 & 7.4 & 0.018 \\
$9.3 \times 10^{-8}$ & 4.9 & 6 & 0.0023 & 4.8 & 0.00012 & 1.7 & 0.052 \\
$1.9 \times 10^{-8}$ & 1.0 & 8 & 0.00048 & 1.0 & 0.00007 & 1.0 & 0.15 \\
$a$
\end{tabular}

${ }^{a}$ Peak A, the retention time $t_{\mathrm{R}}^{\max }=1.29 \mathrm{~min} .{ }^{b}$ Peak B, the retention time $t_{\mathrm{R}}^{\max }=1.48 \mathrm{~min} ; A^{\lambda=300}$ and $A^{\lambda=340}$ are mean values determined from several independent measurements of absorption chromatograms, $N$ - the number of measurements of absorption chromatograms used for the determination of mean values of $A^{\lambda=300}$ for the monomer and $A^{\lambda=340}$ for the dimer.

Therefore, we have performed calculations for very high values of $K_{\mathrm{DM}}=10^{5}-10^{10} \mathrm{M}^{-1}$, covering a wide concentration range to obtain values of $c_{\mathrm{M}}$ and $c_{\mathrm{DM}}$ (Table $\left.\mathrm{S} 2 \dagger\right)$. To employ the results of calculations (Table $\mathrm{S} 2 \dagger$ ) for the confirmation that the peak A originates from dimer and the peak $\mathrm{B}$ from the monomer (Fig. 2, 5 and $\mathrm{S} 1 \dagger$ ), we have calculated relative concentrations of the monomer $c_{\mathrm{M}(\mathrm{rel})}$ and $\operatorname{dimer} c_{\mathrm{DM}(\mathrm{rel})}$, Table 2, using the values of $c_{\mathrm{M}}$ and $c_{\mathrm{DM}}$ presented in Table $\mathrm{S} 2 . \dagger$ As the concentration of C120 increased, relative changes of $c_{\mathrm{DM}(\mathrm{rel})}$ were considerably greater than relative changes of $c_{\mathrm{M}(\mathrm{rel})}$, calculated over the whole range of $K_{\mathrm{DM}}$ values. This means that the peak A observed in absorption chromatograms (Fig. 5), for which relative changes of $A_{\mathrm{DM}(\mathrm{rel})}^{\lambda=340}$ are large (Table 1), should be assigned to the dimer and the peak $\mathrm{B}$, for which changes of $A_{\mathrm{M}(\mathrm{rel})}^{\lambda=300}$ were small, should correspond to the monomer.

Alternatively, the peak B may originate from dimer, while the peak A may arise from a larger aggregate, such as trimer. However, it is unlikely for the monomer content to be so small at very low $\mathrm{C} 120$ concentrations $\left(c_{\mathrm{C} 120}=10^{-7}-10^{-8} \mathrm{M}\right)$ that its peak is undetectable in absorption chromatogram. In such 
Table 2 Relative concentrations of the monomer $C_{M(\text { rel) }}$ and the dimer $C_{D M(r e l)}$ depending on $K_{\mathrm{DM}}$ value (in the range from $1 \times 10^{5}$ to $1 \times 10^{10} \mathrm{M}^{-1}$ ) calculated for concentrations of $\mathrm{C} 120$ in $\mathrm{ACN}$ investigated in this work

\begin{tabular}{|c|c|c|c|c|c|c|c|c|c|c|c|c|c|}
\hline \multirow[b]{2}{*}{$c_{\mathrm{C} 120}[\mathrm{M}]$} & \multirow[b]{2}{*}{$c_{\mathrm{C} 120(\mathrm{rel})}$} & \multicolumn{2}{|c|}{$\begin{array}{l}K_{\mathrm{DM}}=1 \times 10^{5} \\
{\left[\mathrm{M}^{-1}\right]}\end{array}$} & \multicolumn{2}{|c|}{$\begin{array}{l}K_{\mathrm{DM}}=1 \times 10^{6} \\
{\left[\mathrm{M}^{-1}\right]}\end{array}$} & \multicolumn{2}{|c|}{$\begin{array}{l}K_{\mathrm{DM}}=1 \times 10^{7} \\
{\left[\mathrm{M}^{-1}\right]}\end{array}$} & \multicolumn{2}{|c|}{$\begin{array}{l}K_{\mathrm{DM}}=1 \times 10^{8} \\
{\left[\mathrm{M}^{-1}\right]}\end{array}$} & \multicolumn{2}{|c|}{$\begin{array}{l}K_{\mathrm{DM}}=1 \times 10^{9} \\
{\left[\mathrm{M}^{-1}\right]}\end{array}$} & \multicolumn{2}{|c|}{$\begin{array}{l}K_{\mathrm{DM}}=1 \times 10^{10} \\
{\left[\mathrm{M}^{-1}\right]}\end{array}$} \\
\hline & & $c_{\mathrm{DM}(\mathrm{rel})}$ & $c_{\mathrm{M}(\mathrm{rel})}$ & $c_{\mathrm{DM}(\mathrm{rel})}$ & $c_{\mathrm{M}(\mathrm{rel})}$ & $c_{\mathrm{DM}(\mathrm{rel})}$ & $c_{\mathrm{M}(\mathrm{rel})}$ & $c_{\mathrm{DM}(\mathrm{rel})}$ & $c_{\mathrm{M}(\mathrm{rel})}$ & $c_{\mathrm{DM}(\mathrm{rel})}$ & $c_{\mathrm{M}(\mathrm{rel})}$ & $c_{\mathrm{DM}(\mathrm{rel})}$ & $c_{\mathrm{M}(\mathrm{rel})}$ \\
\hline $1.1 \times 10^{-6}$ & 57.9 & 2457 & 49.6 & 838 & 29 & 205.6 & 14.35 & 90 & 9.5 & 66.7 & 8.07 & 60.7 & 7.79 \\
\hline $9.3 \times 10^{-8}$ & 4.9 & 23.9 & 4.89 & 18.8 & 4.35 & 10.5 & 3.24 & 6.47 & 2.54 & 5.3 & 2.31 & 5.04 & 2.24 \\
\hline $1.9 \times 10^{-8}$ & 1.0 & 1.0 & 1.0 & 1.0 & 1.0 & 1.0 & 1.0 & 1.0 & 1.0 & 1.0 & 1.0 & 1.0 & 1.0 \\
\hline
\end{tabular}

a case, the $K_{\mathrm{DM}}$ value should be much greater than $10^{10} \mathrm{M}^{-1}$, which seems improbable. Also the trimerization constant $\left(K_{\mathrm{TM}}\right)$ would be unbelievably high.

\subsection{Dimerization constant, $K_{\mathrm{DM}}$, determination for $\mathrm{C} 120$ in acetonitrile and 1-chlorobutane}

Knowledge of $K_{\mathrm{DM}}$ value permits the investigator to determine the optimal concentration and solvent to be used with a compound. Depending on the dimer stability, $K_{\mathrm{DM}}$ values can vary widely and cover many orders of magnitude. Our calculations presented in Table S1† confirm that the contents of the monomer and the dimer depend very strongly on the concentration of a studied compound and the $K_{\mathrm{DM}}$ value and thus, the monomer-to-dimer concentration ratio for a given concentration of a compound cannot be predicted if the $K_{\mathrm{DM}}$ value is unknown. Concentration of a studied compound that is necessary for the presence of monomer only is also unknown.

As emphasized earlier, large $K_{\mathrm{DM}}$ values can be determined with sensitive UV-VIS or fluorescence emission spectroscopy methods. However, the spectra obtained in these studies are the summary absorption and emission of all species that are present in the sample. Therefore, when determining $K_{\mathrm{DM}}$ on the basis of changes occurring in a UV-VIS absorption spectrum with a change in concentration, it is assumed that only one monomer and one dimer are present in the whole concentration range of the compound studied..$^{1-3}$ Moreover, it is assumed that the presence of isosbestic points indicates the existence of equilibria between the two species. The determination of $K_{\mathrm{DM}}=10^{6}-10^{7} \mathrm{M}^{-1}$ from UV-VIS spectroscopic measurements is also subject to large errors, because despite using low concentrations (usually $10^{-5}-10^{-6} \mathrm{M}$ ), the dimer is the predominant species in the sample, $c_{\mathrm{DM}} / c_{\mathrm{M}}>3$. The very small changes in the absorption spectrum across the whole concentration range make it difficult to establish the presence of an isosbestic point. ${ }^{\mathbf{1}, 2}$ It should be noted that the presence of isosbestic point in absorption spectra of samples with different concentrations of a compound studied does not ensure that only one monomer and one dimer are present. ${ }^{59}$ However, such an assumption has to be made to enable the determination of $K_{\mathrm{DM}}$ value from measurements of UV-VIS spectra of the samples on a spectrophotometer. Moreover, when the absorption spectra of monomer and dimer are similar, the determination of $K_{\mathrm{DM}}$ by UV-VIS methods is very difficult and not very accurate, especially if the absorption spectra are very similar. ${ }^{15,37-41}$

If the dimerization constant $K_{\mathrm{DM}}$ of a compound is very large $\left(10^{8}-10^{9} \mathrm{M}^{-1}\right)$, then even for a very low sample concentration of about $10^{-6} \mathrm{M}$, the content of dimer species in solution will always be greater than that of monomer species (Table $\mathrm{S} 1 \dagger$ ). If the $K_{\mathrm{DM}}$ is $1.5 \times 10^{9} \mathrm{M}^{-1}$ (data obtained for C120 in ACN), the concentration of $\mathrm{C} 120$ should be less than $10^{-9} \mathrm{M}$ (Table S1 $\dagger$ ), to have monomer species content significantly greater than that of dimer species. However, under such conditions, the absorbance of the two species would be too small to measure, even if their molar absorption coefficients $\varepsilon^{\max }$ were fairly large (of the order of $10^{4} \mathrm{~mol}^{-1} \mathrm{dm}^{3} \mathrm{~cm}^{-1}$ ) and quantum yield of fluorescence $\Phi_{\mathrm{F}}<10^{-2}$.

As indicated below, when applying our proposed UHPLC method in tandem with UV-VIS photodiode spectrometry and independently, additionally with an emission detector, the peaks assigned to dimer (A) and monomer (B) species are well resolved and intense enough to be measured with high (DM) and satisfactory (M) accuracy in the absorption chromatograms (see Fig. 5 and $\mathrm{S} 1 \dagger$ ) and in the emission chromatograms (Fig. 6 and $\mathrm{S} 2 \dagger)$ and we were able to calculate $K_{\mathrm{DM}}$ values. Under such conditions, concentrations of the monomer and dimer species can be determined independently using a UHPLC-PDA system (absorbance measurements) or UHPLC-PDA-FL system (absorbance and emission measurements).

3.2.1. Estimation of $K_{\mathrm{DM}}$ value for $\mathrm{C120}$ in ACN. The determination of $K_{\mathrm{DM}}$ with an accuracy much better than one order of magnitude is possible on the basis of a comparison of experimental data obtained from absorption chromatograms (Fig. 5 and Table 1) and from emission chromatograms (Fig. 6 and Table 6) with results of simple calculations (Tables 2 and $\mathrm{S} 2 \dagger$ ) performed for $\mathrm{C} 120$ samples of the same concentrations as those studied experimentally. The calculated $c_{\mathrm{M}} / c_{\mathrm{DM}}$ (Table S2 $\dagger$ ) as well as $c_{\mathrm{M}(\mathrm{rel})}$ and $c_{\mathrm{DM}(\mathrm{rel})}$ (Table 2) for each of the investigated C120 concentrations changed considerably as $K_{\mathrm{DM}}$ changed. The $K_{\mathrm{DM}}$ values were determined by comparing the $c_{\mathrm{M}} / c_{\mathrm{DM}}$ ratio calculated from experimentally determined ratio of $A_{\mathrm{M}}^{\lambda=300} / A_{\mathrm{DM}}^{\lambda=340}$ (taking into account the very similar width of the peaks corresponding to monomer and dimer in the chromatograms and $\varepsilon_{\mathrm{M}}^{\max } \approx 0.5 \varepsilon_{\mathrm{DM}}^{\max }$ ) (Table 1 ) with theoretically calculated ratios of the monomer-to-dimer concentration $\left(c_{\mathrm{M}} / c_{\mathrm{DM}}\right)$ (Table S2 $\dagger$ ). The calculations were performed using three experimentally investigated $\mathrm{C} 120$ concentrations in ACN and the $K_{\mathrm{DM}}$ value in the range $1 \times 10^{5}-1 \times 10^{10} \mathrm{M}^{-1}$. For all $\mathrm{C} 120$ concentrations, the best agreement between the $c_{\mathrm{M}} / c_{\mathrm{DM}}$ ratio calculated from experimental data (Table 1) and the $c_{\mathrm{M}} / c_{\mathrm{DM}}$ ratio calculated theoretically (Table $\mathrm{S} 2 \dagger$ ) was found for $K_{\mathrm{DM}}$ in the range $10^{9}-10^{10} \mathrm{M}^{-1}$. This outcome showed directly that the $K_{\mathrm{DM}}$ for $\mathrm{C} 120$ in ACN lies in this range. 
a)

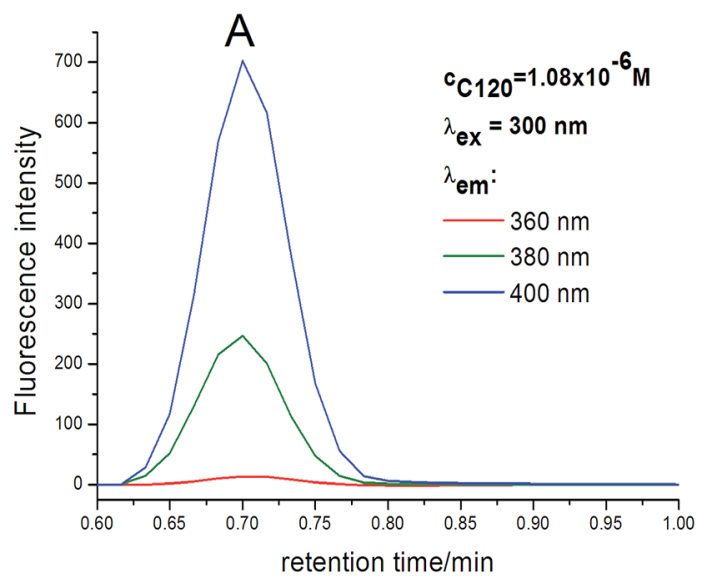

c)

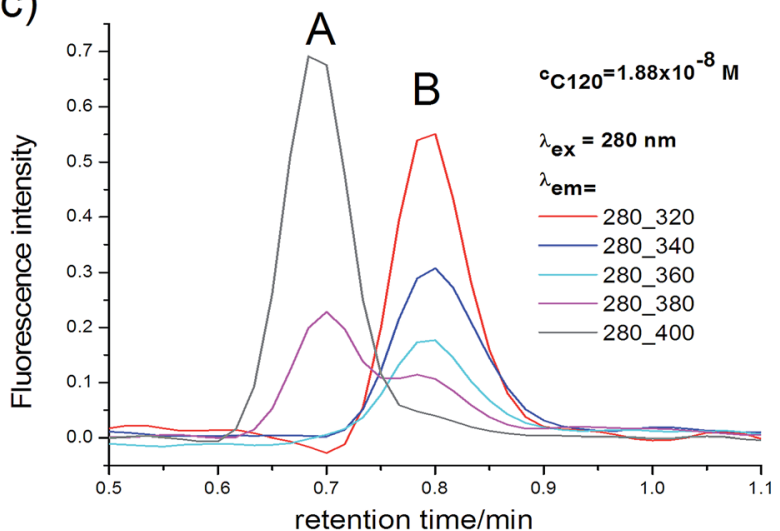

b)

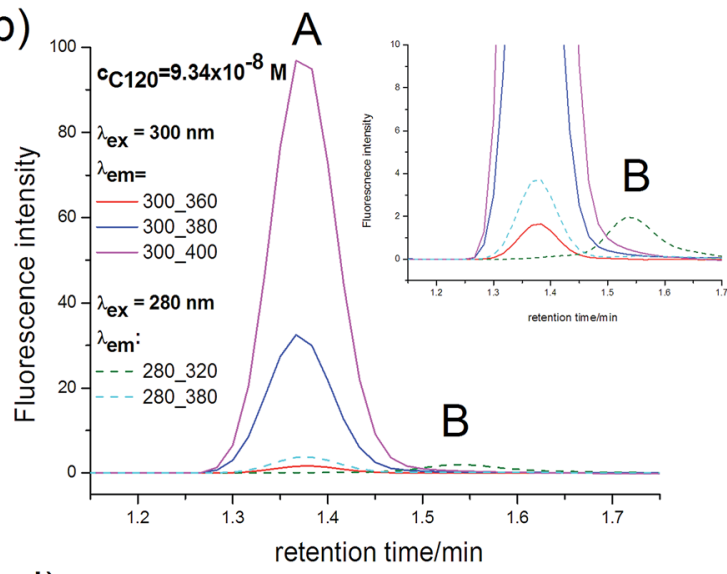

d)

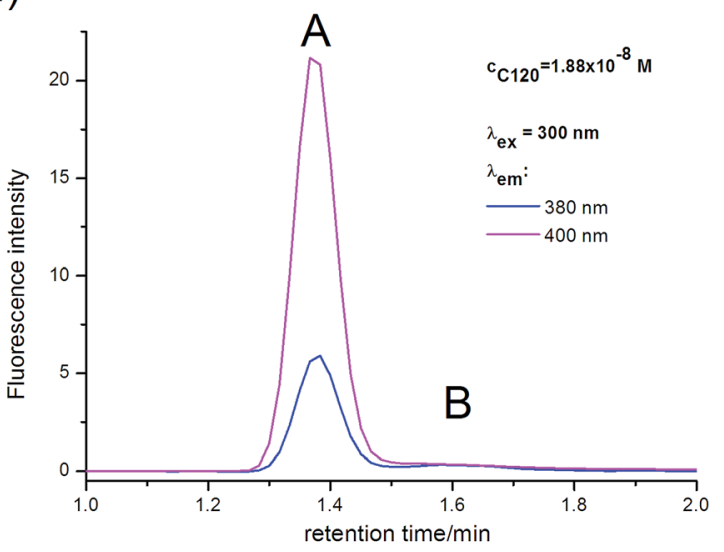

Fig. 6 Emission chromatograms for $\mathrm{C} 120$ samples in $\mathrm{ACN}$ with concentrations of $1.9 \times 10^{-8} \mathrm{M}$ (a), $9.3 \times 10^{-8} \mathrm{M}$ (b), $1.1 \times 10^{-6} \mathrm{M}$ (c). Peak $\mathrm{A}-$ dimer, peak B - monomer; (a and c) flow rate $0.25 \mathrm{ml} \mathrm{min}^{-1}$, (b) flow rate $0.25 \mathrm{ml} \mathrm{min}{ }^{-1}$.

The value of $K_{\mathrm{DM}}$ can also be determined by comparing relative absorbancies at the monomer peak maximum $A_{\mathrm{M}(\mathrm{rel})}^{\lambda=300}$ (peak B) (Table 1), with theoretically calculated values of $c_{\mathrm{M}(\mathrm{rel})}$ (Table 2) and relative absorbancies at the dimer peak maximum $A_{\mathrm{DM}(\mathrm{rel})}^{\lambda=340}$ (peak A) (Table 1), with theoretically calculated values of $c_{\mathrm{DM}(\mathrm{rel})}$ (Table 2). The values of $A_{\mathrm{M}(\mathrm{rel})}^{\lambda=300}$ for the monomer and $A_{\mathrm{DM}(\mathrm{rel})}^{\lambda=340}$ for the dimer were determined at one wavelength therefore, in compliance with the Lambert-Beer law, they depend only on the monomer and dimer concentrations. Thus, these values can be directly compared with the calculated relative concentration of the monomer $\left(c_{\mathrm{M}(\mathrm{rel})}\right)$ and of the dimer $\left(c_{\mathrm{DM}(\mathrm{rel})}\right)$ (Table 2), for the same $\mathrm{C} 120$ concentration. As results from Table 2, the $c_{\mathrm{M}(\mathrm{rel})}$ and $c_{\mathrm{DM}(\mathrm{rel})}$ values strongly depended on $\mathrm{C} 120$ concentration and changed considerably with $K_{\mathrm{DM}}$ value. Having the values of $A_{\mathrm{M}(\mathrm{rel})}^{\lambda=300}$ (the monomer peak) and $A_{\mathrm{DM}(\mathrm{rel})}^{\lambda=340}$ (the dimer peak), determined from absorption chromatograms in the range $c_{\mathrm{C} 120}=1.1 \times 10^{-6}-1.9 \times 10^{-8} \mathrm{M}$ (Fig. 5 and Table 1), as well as calculated values of $c_{\mathrm{M}(\mathrm{rel})}$ and $c_{\mathrm{DM}(\mathrm{rel})}$ (Table 2) in the samples of the same concentrations of C120 (which were investigated experimentally), it was possible to determine the most reliable $K_{\mathrm{DM}}$ values. Both $A_{\mathrm{M}(\mathrm{rel})}^{\lambda=300}$ and $c_{\mathrm{M}(\mathrm{rel})}$ values for the monomer and also $A_{\mathrm{DM}(\mathrm{rel})}^{\lambda=340}$ and $c_{\mathrm{DM}(\mathrm{rel})}$ values for the dimer (Table 1) were similar to calculated $c_{\mathrm{M}(\mathrm{rel})}$ and $c_{\mathrm{DM}(\mathrm{rel})}$ values, when $K_{\mathrm{DM}}$ was very large and fell within the range $1 \times 10^{9}-1 \times 10^{10} \mathrm{M}^{-1}$ (Table 2). Thereby, $K_{\mathrm{DM}}$ values, estimated on the basis of two different relationships and results of the measurements of absorption chromatograms, were very large and similar.

The most sensitive method of accurate determination of very low concentrations is emission spectroscopy, provided that the emission quantum yield $\left(\Phi_{\mathrm{F}}\right)$ is large. The fluorescence of C120 in practically all solvents is very intense, ${ }^{48,49}$ and only in saturated hydrocarbons is somewhat less intense. ${ }^{48}$ In the case of $\mathrm{C} 120\left(c_{\mathrm{C} 120} \sim 10^{-5} \mathrm{M}\right)$ in ACN $\Phi_{\mathrm{F}}=0.63 .^{48}$ Due to this fact, the determination of $\mathrm{M}$ and $\mathrm{DM}$ content on the basis of measurements of emission chromatograms, even at very low C120 concentrations $\left(c_{\mathrm{C} 120}=10^{-8}-10^{-10} \mathrm{M}\right)$ is possible. $K_{\mathrm{DM}}$ values can be estimated using results of the measurements of emission chromatograms (Fig. 6, Tables 6 and 7). Very good quality of these results, particularly for the DM peak, made it possible to precisely determine very large $K_{\mathrm{DM}}$ values including $K_{\mathrm{DM}}=10^{8}-10^{10} \mathrm{M}^{-1}$. The results obtained from emission chromatograms will be presented in the further part of this paper.

3.2.2. An accurate determination of $K_{\mathrm{DM}}$ values for $\mathrm{C} 120$ in ACN and in ChB. In chromatographic measurements, both with the use of absorption detector (PDA) and emission detector (FL), the determination of concentration is based on the area under 
the peak. Absorption chromatograms of a studied compound are recorded at a given wavelength $(\lambda)$, whereas emission chromatograms are measured at a selected excitation wavelength $\left(\lambda_{\mathrm{ex}}\right)$ and a selected emission wavelength $\left(\lambda_{\mathrm{em}}\right)$.

The results of measurements of absorption chromatograms. The determination of concentrations of monomer and dimer in solution requires the knowledge of molar absorption coefficients of both species. The value of molar absorption coefficient for the dimer at the maximum of its long-wavelength absorption band $\left(\lambda^{\max }=340 \mathrm{~nm}\right)$ was determined to be $\varepsilon_{\mathrm{DM}}^{\max }=32600 \mathrm{~mol}^{-1}$ $\mathrm{dm}^{3} \mathrm{~cm}^{-1}$. It was determined directly from the absorption spectra measured using a Jasco V-650 spectrophotometer for C120 solutions in ACN at concentrations in the range $2 \times 10^{-5}-5 \times 10^{-5} \mathrm{M}$, when the dimer species are exclusively present in the sample $\left(c_{\mathrm{DM}} / c_{\mathrm{M}} \geq 100\right)$ (we verified that the AS measured with UV-VIS spectrophotometer was the same as the AS of the dimer measured from the peak A (Fig. 4b)). On the other hand, for the monomer species it was assumed on the basis of the exciton theory ${ }^{60}$ that at the maximum of the long-wavelength absorption band ( $\lambda^{\max }=295 \mathrm{~nm}$ ), the molar absorption coefficient $\varepsilon_{\mathrm{M}}^{\max }$ was half that for the dimer species, i.e., $\varepsilon_{\mathrm{M}}^{\max }=16300 \mathrm{~mol}^{-1} \mathrm{dm}^{3} \mathrm{~cm}^{-1}$.

The dimerization constant $K_{\mathrm{DM}}$ for $\mathrm{C} 120$ in ACN was determined from the equation: ${ }^{\mathbf{1 , 6 1 , 6 2}}$

$$
K_{\mathrm{DM}}=(1-\alpha) /\left(2 \alpha^{2} c_{\mathrm{C} 120}\right)
$$

where $\alpha$ (mole fraction of monomer species) is defined as $\alpha=$ $c_{\mathrm{M}} / c_{\mathrm{C} 120}$ and $c_{\mathrm{C} 120}=c_{\mathrm{M}}+2 c_{\mathrm{DM}}$.

The concentration of the dimer $\left(c_{\mathrm{DM}}\right)$ was calculated from the area under the chromatographic peak $\mathrm{A}\left(P_{\mathrm{DM}}\right)$, taking into account the value of $\varepsilon(\lambda)$ for $\lambda$ at which the dimer peak was measured in the absorption chromatogram. The concentration of the monomer was calculated from the area under the chromatographic peak B $\left(P_{\mathrm{M}}\right)$, taking into account the value of $\varepsilon(\lambda)$ for $\lambda$ at which the monomer peak was measured in the absorption chromatogram.

In the studies carried out at very low C120 concentrations, while calculating the dimer concentration, the value of $P_{\mathrm{DM}}$ and molar absorption coefficient of the dimer $\left(\varepsilon_{\mathrm{DM}}^{\max }\right)$ were determined at $\lambda=340 \mathrm{~nm}$. It is worth mentioning that the same concentrations of the dimer were obtained when $P_{\mathrm{DM}}$ and $\varepsilon_{\mathrm{DM}}$ were determined at $\lambda=330$ and $350 \mathrm{~nm}$. On the other hand, to calculate the monomer concentration, $P_{\mathbf{M}}$ and $\varepsilon_{\mathbf{M}}$ were determined at $\lambda=300 \mathrm{~nm}$ and $310 \mathrm{~nm}$.

The dimerization constant $K_{\mathrm{DM}}$, determined using the absorption chromatograms for C120 solutions in ACN in the concentrations range from $1.1 \times 10^{-6}$ to $9.3 \times 10^{-8} \mathrm{M}$, was found to be very large and covered a relatively narrow range $\left(K_{\mathrm{DM}}=0.9-2.6 \times 10^{9} \mathrm{M}^{-1}\right.$, Table 3$)$. The mean value of $K_{\mathrm{DM}}=$ $1.5 \times 10^{9} \mathrm{M}^{-1}$ was calculated for two concentrations $\left(c_{\mathrm{C} 120}=1.1\right.$ $\times 10^{-6} \mathrm{M}$ and $c_{\mathrm{C} 120}=9.3 \times 10^{-8} \mathrm{M}$ ) for which the error of the determined $K_{\mathrm{DM}}$ is the smallest. The obtained results show that $K_{\mathrm{DM}}$ does not depend on $\mathrm{C} 120$ concentration and wavelength at which the monomer concentration was derived from absorption chromatograms (Table 3 ). $K_{\mathrm{DM}}$ also was independent of conditions used in absorption chromatogram measurements (i.e., flow rate).
The $K_{\mathrm{DM}}$ values determined at each concentration (Table 3) are mean values calculated from several independent and reproducible absorption chromatograms (see Fig. S1 $\dagger$ ). The mean value of $K_{\mathrm{DM}}$ determined for the sample with the concentration of $1.1 \times 10^{-6} \mathrm{M}$ was very similar to $K_{\mathrm{DM}}$ values determined for single measurements. In the case of the aforementioned sample, $\mathrm{S} /$ $\mathrm{N}=1500$ for the dimer peak, while for the monomer peak, $\mathrm{S} / \mathrm{N}$ $=25$. With a relatively large measurement error of $P_{\mathrm{M}}$ (for the monomer peak $\mathrm{S} / \mathrm{N}=3$ ) and $P_{\mathrm{DM}}$ (for the dimer peak $\mathrm{S} / \mathrm{N}=25$ ), determined from eight absorption chromatograms measured for the sample with $c_{\mathrm{C} 120}=1.9 \times 10^{-8} \mathrm{M}$, values of $K_{\mathrm{DM}}$ covered a relatively wide range: $K_{\mathrm{DM}}=(0.4-3.0) \times 10^{9} \mathrm{M}^{-1}$. Although the mean value of $K_{\mathrm{DM}}$ determined from eight measurements was close to the mean value of $K_{\mathrm{DM}}$ determined for samples with greater concentrations, the lower reliability of $K_{\mathrm{DM}}$ value determined for the sample with $c=1.9 \times 10^{-8} \mathrm{M}$ led us to omit this value from the determination of the final value of $K_{\mathrm{DM}}=1.5 \times 10^{9} \mathrm{M}^{-1}$.

The necessity of conducting research on extremely low concentrations of $\mathrm{C} 120$ inevitably entailed measurements of absorption chromatograms in which the dimer peak, and particularly the monomer peak, had exceptionally low intensity. At $c_{\mathrm{C} 120}=1.9 \times 10^{-8} \mathrm{M}, A_{\mathrm{M}}^{\lambda=300}<1 \times 10^{-4}$ for the monomer peak, and $A_{\mathrm{DM}}^{\lambda=340} \sim 5 \times 10^{-4}$ for the dimer peak. To check whether the above values agreed with the expected ones, they were compared with calculated $A_{\mathrm{DM}}^{\lambda=340}$ for DM and $A_{\mathrm{M}}^{\lambda=300}$ for M. For samples with experimentally studied concentrations of C120 and for the determined value of $K_{\mathrm{DM}}=1.5 \times 10^{9} \mathrm{M}^{-1}$, calculations were performed of $c_{\mathrm{M}}$ and $c_{\mathrm{DM}}$ values. Since we knew that $\varepsilon_{\mathrm{DM}}^{\max }=32600 \mathrm{M}^{-1} \mathrm{~cm}^{-1}$ for dimer and it was assumed on the basis of the exciton theory, ${ }^{60}$ that $\varepsilon_{\mathrm{M}}^{300}=15500 \mathrm{M}^{-1} \mathrm{~cm}^{-1}$ for monomer, as well as $l=2.5 \mathrm{~cm}$ (in the PDA detector), we were able to calculate $A_{\mathrm{DM}}^{\lambda=340}$ and $A_{\mathrm{M}}^{\lambda=300}$ on the basis of the LambertBeer law. Both the shape of the monomer and dimer peaks, as well as their width in absorption chromatograms were very similar, at least for the range of C120 concentrations $c_{\mathrm{C} 120}=1.0 \times 10^{-6}-9.3 \times 10^{-8} \mathrm{M}$ (Fig. 5), allowing us to directly compare experimentally obtained $A_{\mathrm{M}}^{\lambda=300}$ and $A_{\mathrm{DM}}^{\lambda=340}$ with those calculated theoretically. A very good agreement was obtained between experimentally determined and calculated $A_{\mathrm{DM}}^{\lambda=340}$ values for all $c_{\mathrm{C} 120}$ concentrations (Table 4 ). Also for the sample with the highest concentration, $c_{\mathrm{C} 120}=1.1 \times 10^{-6} \mathrm{M}$, there is a very good agreement between the experimental $A_{\mathrm{M}}^{\lambda=300}=5.3 \times 10^{-4}(\mathrm{~S} / \mathrm{N}>$ 20) and calculated $A_{\mathrm{M}}^{\lambda=300}=5.0 \times 10^{-4}$ values (Table 4 ) (the latter was calculated assuming that $\left.\varepsilon_{\mathrm{M}}^{300}=15500 \mathrm{M}^{-1} \mathrm{~cm}^{-1}\right)$. This agreement proves that the assumption that $\varepsilon_{\mathrm{M}}^{\max }=0.5 \varepsilon_{\mathrm{DM}}^{\max }$, made on the basis of the exciton model, ${ }^{60}$ is correct. Therefore, one can expect that the value of $K_{\mathrm{DM}}=1.5 \times 10^{9} \mathrm{M}^{-1}$, determined from absorption chromatograms using the above assumption, is also correct. Moreover very important is the fact that, an independent confirmation was provided by results of the measurements of emission chromatograms (see below).

Since UHPLC system enables to perform measurements of absorption chromatograms for very low concentrations $\left(10^{-7}\right.$ $10^{-8} \mathrm{M}$ ), if $\varepsilon(\lambda) \sim 10^{4} \mathrm{M}^{-1} \mathrm{~cm}^{-1}$, therefore the monomer content in samples with $c_{\mathrm{C} 120}=1.9 \times 10^{-8} \mathrm{M}$ and $c_{\mathrm{C} 120}=9.3 \times 10^{-8} \mathrm{M}$ was relatively large, in spite of exceptionally high value of $K_{\mathrm{DM}}$. 
Table 3 The effect of $\mathrm{C} 120$ concentration in $\mathrm{ACN}$ and wavelength used in absorption chromatogram measurements on the mole fraction of monomer $\left(\alpha_{300}\right.$ and $\left.\alpha_{310}\right)$ and $K_{\mathrm{DM}}$ value

\begin{tabular}{llllllll}
\hline$c_{\mathrm{C} 120}[\mathrm{M}]$ & $P_{\mathrm{DM}}^{340}$ & $P_{\mathrm{M}}^{300}$ & $P_{\mathrm{M}}^{310}$ & $\alpha_{300}\left[\times 10^{-2}\right]$ & $\alpha_{310}\left[\times 10^{-2}\right]$ & $K_{\mathrm{DM}}^{300}\left[\times 10^{9}\right]\left[\mathrm{M}^{-1}\right]$ & $K_{\mathrm{DM}}^{310}\left[\times 10^{9}\right]\left[\mathrm{M}^{-1}\right]$ \\
\hline $1.1 \times 10^{-6 a}$ & $1.47 \times 10^{-3}$ & $2.7 \times 10^{-5}$ & $3.3 \times 10^{-5}$ & 1.8 & 2.2 & 1.4 & 0.9 \\
$1.1 \times 10^{-6 b}$ & $6.29 \times 10^{-4}$ & $1.4 \times 10^{-5}$ & $1.5 \times 10^{-5}$ & 2.2 & 2.3 & 0.9 & 0.9 \\
$9.3 \times 10^{-8 a}$ & $1.13 \times 10^{-4}$ & $6.1 \times 10^{-6}$ & $5.2 \times 10^{-6}$ & 5.1 & 4.4 & 2.0 & 2.6 \\
$1.9 \times 10^{-8 a}$ & $2.6 \times 10^{-5}$ & $4.5 \times 10^{-6}$ & $4.4 \times 10^{-6}$ & 17 & 14 & 0.8 & 1.0
\end{tabular}

${ }^{a}$ Flow rate $-0.25 \mathrm{ml} \mathrm{min}^{-1} \cdot{ }^{b}$ Flow rate $-0.5 \mathrm{ml} \mathrm{min}^{-1} ; P_{\mathrm{M}}^{300}$ and $P_{\mathrm{M}}^{310}$ - area under chromatographic peak of the monomer (peak B), $P_{\mathrm{DM}}^{340}-$ area under chromatographic peak of the dimer (peak A).

Table 4 Comparison of experimentally measured mean absorbance values (exp) for monomer and dimer with the values calculated (cal) for $K_{\mathrm{DM}}$ $=1.5 \times 10^{9} \mathrm{M}^{-1}$ obtained on the basis of experimental results for $\mathrm{C} 120$ in $\mathrm{ACN}$

\begin{tabular}{lllllll}
\hline$c_{\mathrm{C} 120}[\mathrm{M}]$ & $A_{\mathrm{DM}}^{\lambda=340} \mathrm{cal}$ & $A_{\mathrm{DM}}^{\lambda=340} \exp$ & $A_{\mathrm{M}}^{\lambda=300} \mathrm{cal}$ & $A_{\mathrm{M}}^{\lambda=300} \exp$ & $A_{\mathrm{M}}^{\lambda=300} / A_{\mathrm{DM}}^{\lambda=340} \mathrm{cal}$ & $A_{\mathrm{M}}^{\lambda=300} / A_{\mathrm{DM}}^{\lambda=340} \exp$ \\
\hline $1.1 \times 10^{-6}$ & $2.92 \times 10^{-2}$ & $2.93 \times 10^{-2}$ & $5.0 \times 10^{-4}$ & $5.3 \times 10^{-4}$ & 0.017 & 0.018 \\
$9.3 \times 10^{-8}$ & $2.38 \times 10^{-3}$ & $2.30 \times 10^{-3}$ & $1.4 \times 10^{-4}$ & $1.2 \times 10^{-4}$ & 0.059 & 0.052 \\
$1.9 \times 10^{-8}$ & $4.51 \times 10^{-4}$ & $4.8 \times 10^{-4}$ & $6.1 \times 10^{-5}$ & $7.0 \times 10^{-5}$ & 0.135 & 0.150
\end{tabular}

For the sample with the lowest concentration, the monomer content was about $30 \%$ (Table 5 ). Due to this fact, the $c_{\mathrm{M}} / c_{\mathrm{DM}}$ ratio for the sample with the concentration of $1.9 \times 10^{-8} \mathrm{M}$ was relatively large and 7 times greater than that for the sample with the concentration of $1.1 \times 10^{-6} \mathrm{M}$, in which the monomer content was about $4 \%$ (Table 5 ).

The values of $c_{\mathrm{M}}, c_{\mathrm{DM}}$ and $c_{\mathrm{M}} / c_{\mathrm{DM}}$ determined from absorption chromatograms and calculated by taking the value of $K_{\mathrm{DM}}=1.5 \times 10^{9} \mathrm{M}^{-1}$ closely agreed with each other for C120 in the concentration range of $10^{-6}-10^{-8} \mathrm{M}$ (Table 5). This means that both the measured absorption chromatograms (Fig. 5) and $c_{\mathrm{M}}$ and $c_{\mathrm{DM}}$ values calculated on their basis indicate that the monomer-dimer model assumed for C120 in ACN and the determined very high $K_{\mathrm{DM}}$ value are correct.

Although all results presented thus far are in agreement with the assumed model indicating the presence monomer and dimer, it is possible that trimer and not the dimer is present in addition to the monomer. To establish whether it is possible in the case of $\mathrm{C} 120$ in $\mathrm{ACN}$, the value of trimerization constant $\left(K_{\mathrm{TM}}\right)$ was determined for a sample with the concentration of $1.1 \times 10^{-6} \mathrm{M}$ (Fig. 5a and b) for which the monomer concentration (peak B) and the trimer concentration (peak A) would be the same as the concentrations determined from intensities of peaks $\mathrm{A}$ and $\mathrm{B}$ in the absorption chromatogram (assuming $\varepsilon_{\mathrm{TM}}^{\max }=\varepsilon_{\mathrm{DM}}^{\max }$ ). The determined $K_{\mathrm{TM}}$ value must be equal to
$1 \times 10^{17} \mathrm{M}^{-2}$. For the above value of $K_{\mathrm{TM}}$, the calculated concentration ratios $c_{\mathrm{M}} / c_{\mathrm{TM}}$ for the samples with two lower concentrations $\left(c_{\mathrm{C} 120}=1.9 \times 10^{-8} \mathrm{M}\right.$ and $\left.9.3 \times 10^{-8} \mathrm{M}\right)$ clearly differed from the values obtained experimentally (Table S3 $\dagger$ ), which were in a very good agreement with experimentally determined $c_{\mathrm{M}} / c_{\mathrm{DM}}$ ratios (Table 5 ). This outcome directly showed that the peak A cannot originate from trimer.

The results of measurements of emission chromatograms. Emission spectra of $\mathrm{C} 120\left(c_{\mathrm{C} 120}=10^{-4}-10^{-6} \mathrm{M}\right)$ in solvents of different properties, including ACN, have been published many times, ${ }^{\mathbf{4 8 , 4 9}}$ likewise $\Phi_{\mathrm{F}}$ values $^{\mathbf{4 8}}$ and lifetimes in the $\mathrm{S}_{1}$ state. The same ES and the value of $\Phi_{\mathrm{F}}=0.63$, as those reported earlier, ${ }^{48} \mathrm{we}$ have obtained when measuring ES of C120 $\left(c_{\mathrm{C} 120} \sim 10^{-5}-10^{-6} \mathrm{M}\right)$ in ACN on a spectrofluorimeter. Taking into consideration C120 concentrations used in our studies, one can assume, on the basis of the above presented absorption chromatograms (Fig. 5) and determined $K_{\mathrm{DM}}=1.5 \times 10^{9} \mathrm{M}^{-1}$, that in the emission measurements performed by us in this study and earlier, ${ }^{48,49} c_{\mathrm{DM}}$ $\geq 100 c_{\mathrm{M}}$. Moreover, if the position of the long-wavelength band in absorption spectra of M and DM (Fig. 3 and 4) is taken into consideration, it becomes obvious that the emission observed hitherto for $\lambda_{\text {ex }} \sim 340 \mathrm{~nm}$ originates from DM and not, as was believed, from $\mathbf{M}$ ! Although emission properties of $\mathbf{M}$ are unknown, one can expect that its ES is short-wavelength shifted

Table 5 Comparison of experimentally obtained concentration values (exp) for monomer and dimer with calculated values (cal) for $K_{\mathrm{DM}}=1.5 \times$ $10^{9} \mathrm{M}^{-1}$ (obtained on the basis of experimental results) for C120 concentrations investigated in this work ${ }^{a}$

\begin{tabular}{|c|c|c|c|c|c|c|c|c|c|c|}
\hline$c_{\mathrm{C} 120}[\mathrm{M}]$ & $c_{\mathrm{DM}}[\mathrm{M}] \mathrm{cal}$ & $c_{\mathrm{DM}}[\mathrm{M}] \exp$ & $c_{\mathrm{M}}[\mathrm{M}] \mathrm{cal}$ & $c_{\mathrm{M}}[\mathrm{M}] \exp$ & $\begin{array}{l}c_{\mathrm{DM}}[\%] \\
\mathrm{cal}\end{array}$ & $\begin{array}{l}c_{\mathrm{DM}}[\%] \\
\exp \end{array}$ & $\begin{array}{l}c_{\mathrm{M}}[\%] \\
\mathrm{cal}\end{array}$ & $\begin{array}{l}c_{\mathrm{M}}[\%] \\
\exp \end{array}$ & $c_{\mathrm{M}} / c_{\mathrm{DM}}$ cal & $c_{\mathrm{M}} / c_{\mathrm{DM}} \exp$ \\
\hline $1.1 \times 10^{-6}$ & $5.4 \times 10^{-7}$ & $5.4 \times 10^{-7}$ & $1.9 \times 10^{-8}$ & $2.2 \times 10^{-8}$ & 96.6 & 96.1 & 3.4 & 3.9 & 0.04 & 0.04 \\
\hline $9.3 \times 10^{-8}$ & $4.4 \times 10^{-8}$ & $4.4 \times 10^{-8}$ & $5.4 \times 10^{-9}$ & $5.2 \times 10^{-9}$ & 89.0 & 89.4 & 11.0 & 10.6 & 0.12 & 0.12 \\
\hline $1.9 \times 10^{-8}$ & $8.3 \times 10^{-9}$ & $8.1 \times 10^{-9}$ & $2.4 \times 10^{-9}$ & $2.8 \times 10^{-9}$ & 77.9 & 74.0 & 22.1 & 26.0 & 0.29 & 0.35 \\
\hline
\end{tabular}

${ }^{a} c_{\mathrm{M}}(\exp )$ was determined from the monomer peak area $\left(P_{\mathrm{M}}^{300}\right) ; c_{\mathrm{DM}}(\exp )$ was determined from the dimer peak area $\left(P_{\mathrm{DM}}^{340}\right)$. 
relative to ES of DM, analogously to their long-wavelength band in AS. Also $\Phi_{\mathrm{F}}$ value of the monomer should be large.

Emission chromatograms, measured on the UHPLC-PDA-FL system immediately after absorption chromatograms, are shown in Fig. 6. Due to relatively high concentration of DM and its $\Phi_{\mathrm{F}}=0.63$, only a DM-originated peak is visible in the longwavelength range $\left(\lambda_{\mathrm{em}} \geq 380 \mathrm{~nm}\right)$ in the emission chromatogram of the sample with the concentration of $c_{\mathrm{C} 120}=1.1 \times 10^{-6} \mathrm{M}$ (Fig. 6a). The mentioned peak is also visible for the same $\lambda_{\mathrm{em}}$ in the case of samples with lower concentrations (Fig. $6 \mathrm{~b}$ and c), however, its intensity is considerably lower in accordance with the relation $I_{\mathrm{F}} \sim \Phi_{\mathrm{F}}\left(1-10^{-\mathrm{A} \lambda_{\text {ex }}}\right)$. In Fig. $6 \mathrm{~b}$ and $\mathrm{c}$ visible is also another peak originating from $\mathrm{M}$, whose intensity strongly depends on $\lambda_{\mathrm{em}}$. The peak's intensity increases for shorter and shorter $\lambda_{\mathrm{em}}$ (Fig. 6c) and is the highest for $\lambda_{\mathrm{em}}=320 \mathrm{~nm}$ (Fig. $6 \mathrm{~b}$ and c). The retention time of $\mathrm{M}$ and DM in emission chromatograms is the same as that of $\mathrm{M}$ and DM in absorption chromatograms (after elimination of the difference in $t_{\mathrm{R}}^{\max }$ values, originating from the configuration of the UHPLC-PDA-FL system, in both chromatograms). Unfortunately, ES measurements are not possible using emission detector. However, on the basis of the obtained emission chromatograms (Fig. 6b and c) one can assume that maximum in the emission spectrum of $\mathrm{M}$ is located near $\lambda_{\mathrm{F}}^{\max } \sim 320 \mathrm{~nm}$, so it is strongly short-wavelength shifted relative to that in the fluorescence spectrum of $\mathrm{DM}\left(\lambda_{\mathrm{F}}^{\max } \sim 410 \mathrm{~nm}\right)$, analogously as in AS. The initial part of the emission spectrum of DM at the short-wavelength side is located at $\lambda_{\mathrm{F}} \geq 350 \mathrm{~nm} .{ }^{48}$ This is why the DM peak is not visible in emission chromatograms for $\lambda_{\mathrm{em}} \leq 340 \mathrm{~nm}$ (Fig. $6 \mathrm{~b}$ and c), despite relatively high concentration of the dimer.

Although the $\mathrm{M}$ peak is well visible in emission chromatograms for very low concentrations $c_{\mathrm{C} 120} \leq 9.3 \times 10^{-8} \mathrm{M}$ (Fig. $6 \mathrm{~b}$ and $\mathrm{c}$ ), however, only a very intense DM peak has been employed for the determination of $K_{\mathrm{DM}}$ values from emission chromatograms. For the latter peak and the concentration $c_{\mathrm{C} 120}=1.9 \times 10^{-8} \mathrm{M}$ (Fig. 6d), for $\lambda_{\mathrm{em}}=380 \mathrm{~nm}$, the ratio of $\mathrm{S} / \mathrm{N}=600$ and for $\lambda_{\mathrm{em}}=400$ and $420 \mathrm{~nm}$ the $\mathrm{S} / \mathrm{N}$ ratio is even considerably greater. Therefore, one can expect that DM peak areas $\left(P_{\mathrm{DM}}\right)$ determined from emission chromatograms and calculated $P_{\mathrm{DM}(\mathrm{rel})}$, as well as $K_{\mathrm{DM}}$ values determined on their basis will be reliable and encumbered with small error. $P_{\mathrm{DM}}$ values were measured for $\lambda_{\mathrm{ex}}$ $(300,340 \mathrm{~nm})$ and $\lambda_{\mathrm{em}}(380,400,420 \mathrm{~nm})$ chosen in such a way that the DM peak was intense even for the lowest $\mathrm{C} 120$ concentrations (Fig. 6). The values of $P_{\mathrm{DM}(\mathrm{rel})}$ and $P_{\mathrm{DM}}$, given for the concentration $c_{\mathrm{C} 120}=1.9 \times 10^{-8} \mathrm{M}$ were presented in Table 6 . The $P_{\mathrm{DM}(\mathrm{rel})}$ values are similar for all emission chromatograms. The experimentally determined $P_{\mathrm{DM}}$ correspond directly to DM concentrations $\left(c_{\mathrm{DM}}\right)$, (Table $\left.\mathrm{S} 4 \dagger\right)$ and $P_{\mathrm{DM}(\mathrm{rel})}$ correspond to $c_{\mathrm{DM}(\mathrm{rel})}$ values. To determine $K_{\mathrm{DM}}$ values for measured emission chromatograms we have calculated $c_{\mathrm{DM}(\mathrm{rel})}$ values for samples with the same concentrations of the $\mathrm{C} 120$ as those studied experimentally (Table 7 ). The calculations were performed for $K_{\mathrm{DM}}$ in the range of $(0.5-3.0) \times 10^{9} \mathrm{M}^{-1}$. This range was chosen in such a way that it included $K_{\mathrm{DM}}=1.5 \times 10^{9} \mathrm{M}^{-1}$ for C120 in ACN, determined from absorption chromatograms (Fig. 5 and Table 3). In Table 6 presented are $K_{\mathrm{DM}}$ values determined by comparing $c_{\mathrm{DM}(\mathrm{rel})}$ obtained from emission chromatograms (Fig. 6) with $c_{\mathrm{DM}(\mathrm{rel})}$ calculated theoretically (Table 7).

The $K_{\mathrm{DM}}$ values determined for $\mathrm{C} 120$ in ACN on the basis of the measured absorption chromatograms (Fig. 5) and emission chromatograms (Fig. 6) are given in Table 8. All $K_{\mathrm{DM}}$ values calculated from eqn (2) or obtained from $c_{\mathrm{DM}(\mathrm{rel})}$ are similar (Table 8). The mean value of $K_{\mathrm{DM}}$ is $1.5 \times 10^{9} \mathrm{M}^{-1}$ and does not depend on $\mathrm{C} 120$ concentration.

The study of the solvent effect on $K_{\mathrm{DM}}$ value was carried out for many compounds using NMR and UV-VIS techniques. The $K_{\mathrm{DM}}$ value increases, as expected, with a decrease in the energy of interactions with a solvent. ${ }^{1-3,6,16}$ However, sometimes the observed effect of a solvent on $K_{\mathrm{DM}}$ value is surprising. In our work, in addition to the determination of $K_{\mathrm{DM}}$ in a polar solvent such as $\operatorname{ACN}\left(f\left(\varepsilon, n^{2}\right)=0.306\right)$, we present results of $K_{\mathrm{DM}}$ determination in a less polar solvent such as 1-chlorobutane (ChB) $\left.f\left(\varepsilon, n^{2}\right)=0.204\right)$. This permits to expect in the case of the latter solvent even a higher $K_{\mathrm{DM}}$ value than in that of ACN. In emission chromatogram, likewise in absorption chromatogram, there are two peaks originating from $\mathrm{M}$ and DM (not shown) and, contrary to the measurement in ACN, the retention time $\left(t_{\mathrm{R}}^{\max }\right)$ of $\mathrm{M}$ is somewhat shorter $(\sim 6 \mathrm{~s}$ for flow rate $\left.0.25 \mathrm{ml} \mathrm{min}^{-1}\right)$, than $t_{\mathrm{R}}^{\max }$ of DM. Since a higher $K_{\mathrm{DM}}$ value was expected in ChB than in ACN, we have used even lower C120 concentrations than those in ACN to get a sufficiently large $c_{\mathrm{M}} /$ $c_{\mathrm{DM}}$ ratio in the sample with the lowest concentration $\left(c_{\mathrm{C} 120}=6.82 \times 10^{-9} \mathrm{M}\right)$. The $P_{\mathrm{DM}}$ values were measured for $\lambda_{\mathrm{ex}}$ $(300,340 \mathrm{~nm})$ and $\lambda_{\mathrm{em}}(380,400,420 \mathrm{~nm})$ chosen in such a way that the DM peak was intense even for the lowest C120 concentrations. The results obtained for DM are presented in Table 9 in which experimental $P_{\mathrm{DM}}$ values obtained for the lowest C120 concentration and calculated $P_{\mathrm{DM}(\mathrm{rel})}$ values are given for all concentrations. The $P_{\mathrm{DM}(\mathrm{rel})}$ values are similar for all emission chromatograms. By using calculated $c_{\mathrm{DM}}$ values (Table S5 $\dagger$ ) and calculated $c_{\text {DMrel }}$ values (Table S6 $\dagger$ ), for samples with

Table 6 The effect of $\mathrm{C} 120$ concentration in $\mathrm{ACN}$ and excitation and emission wavelengths in a measured emission chromatogram on the emission relative intensity of $\mathrm{DM},\left(P_{\mathrm{DM}(\mathrm{rel})}\right)$ and $K_{\mathrm{DM}}$ value

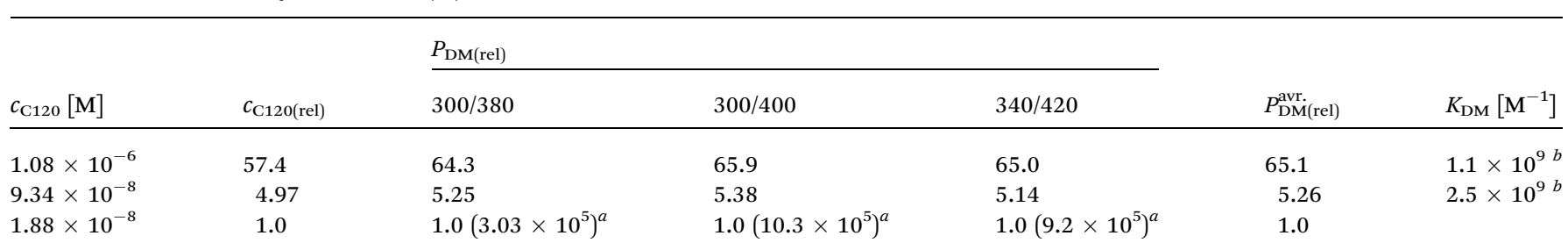

${ }^{a}$ DM peak area $\left(P_{\mathrm{DM}}\right)$ is given in parentheses. ${ }^{b}$ See Table 7. 
Table 7 Relative concentrations of the dimer $C_{D M}(r e l)$ depending on $K_{\mathrm{DM}}$ value (in the range from $0.5 \times 10^{9} \mathrm{M}^{-1}$ to $3.0 \times 10^{9} \mathrm{M}^{-1}$ ), calculated for concentrations of $\mathrm{C} 120$ in ACN investigated in this work

\begin{tabular}{|c|c|c|c|c|c|c|c|}
\hline & $c_{\mathrm{C} 120(\mathrm{rel})}$ & \multicolumn{6}{|l|}{$K_{\mathrm{DM}}\left[\mathrm{M}^{-1}\right]$} \\
\hline $1.08 \times 10^{-6}$ & 57.4 & 70.0 & 66.0 & 64.5 & 62.8 & 62.8 & 62.4 \\
\hline $9.34 \times 10^{-8}$ & 4.97 & 5.636 & 5.425 & 5.346 & 5.29 & 5.26 & 5.23 \\
\hline
\end{tabular}

Table 8 The values of $K_{\mathrm{DM}}$ for $\mathrm{C} 120$ in $\mathrm{ACN}$ determined on the basis of the absorption and emission chromatograms measured on the UHPLC-PDA-FL system

\begin{tabular}{llll}
\hline$c_{\mathrm{C} 120}(\mathrm{M})$ & $K_{\mathrm{DM}} \times 10^{9}\left(\mathrm{M}^{-1}\right)$ & & \\
\hline $1.1 \times 10^{-6}$ & $1.2^{a}$ & $1.0^{b}$ & $1.1^{c}$ \\
$9.3 \times 10^{-8}$ & $2.3^{a}$ & $1.0^{b}$ & $2.5^{c}$ \\
$1.9 \times 10^{-8}$ & $0.9^{a}$ & - & -
\end{tabular}

${ }^{a}$ Obtained from absorption chromatograms and eqn (2), see Table 3. ${ }^{b}$ Obtained using the $c_{\mathrm{DM}(\mathrm{rel})}$ values determined from the absorption chromatograms, see Table 5; for details see text. ${ }^{c}$ Obtained from the $c_{\mathrm{DM}(\mathrm{rel})}$ values determined from the emission chromatograms, see Table 6; for details see text.

the same C120 concentrations as those investigated experimentally, we have determined the value of $K_{\mathrm{DM}}=9 \times 10^{9} \mathrm{M}^{-1}$. A clearly higher $K_{\mathrm{DM}}$ value determined in ChB compared to that in $\mathrm{ACN}$ is in agreement with the higher value of $E_{\mathrm{DM}}=7300 \mathrm{~cm}^{-1}$ in $\mathrm{ChB}^{58}$ than in $\mathrm{ACN}, E_{\mathrm{DM}}=7000 \mathrm{~cm}^{-1} .^{58}$

Conclusions on the determination of very large $K_{D M}$ values on the basis of measurements of absorption chromatograms and emission chromatograms using a UHPLC-PDA-FL system. This is the first reported application of the UHPLC-PDA-FL method for the determination of a $K_{\mathrm{DM}}$ value. This method permits the separation of $\mathrm{M}$ from $\mathrm{DM}$ and provides a higher sensitivity than any other method used thus far. With the use of a UHPLC-PDA-FL system experimental data needed for the determination of $K_{\mathrm{DM}}$ are obtained directly from absorption and emission chromatograms. Isocratic elution mode with ACN and ChB was used and no buffer was added to the eluent so that the system peaks ("ghost peaks") were avoided. ${ }^{63-68}$ By carefully controlling the number of peaks in the absorption and emission chromatograms, their intensities and shapes, measured in a wide range of wavelengths $(\lambda)$ (absorption chromatogram) or wavelengths of the excitation $\left(\lambda_{\mathrm{ex}}\right)$ and emission $\left(\lambda_{\mathrm{em}}\right)$, (emission chromatogram), we were confident that in the results presented in this work all chromatographic peaks came only from the species formed by C120. In all chromatograms of C120 samples in ACN and in ChB with the concentration of $10^{-6}-10^{-8} \mathrm{M}$, the same two peaks with very similar retention times, shapes and absorption spectra were always present.

The results obtained for $\mathrm{C} 120$ in ACN and ChB confirm that by using the UHPLC-PDA-FL one can determine very high $K_{\mathrm{DM}}$ values, even of order $10^{10} \mathrm{M}^{-1}$. For such high $K_{\mathrm{DM}}$ values, the maximum monomer content will be no more than $10 \%$, however, this is enough for the determination of a reliable $K_{\mathrm{DM}}$ value, particularly when making use of the emission chromatograms of compounds with a large $\Phi_{\mathrm{F}}$. A good illustration is provided by the emission chromatograms obtained for C120 in ACN (Fig. 6). The peak of M, and particularly that of DM, are characterized by a relatively high intensity, even for very low concentration, $c_{\mathrm{C} 120} \sim 1.9 \times 10^{-8} \mathrm{M}$. This is a consequence of a very high value of $\Phi_{\mathrm{F}}=0.63$ for DM, as well as high $\Phi_{\mathrm{F}}$ for M. Taking into account good quality and reproducibility of the results presented and the way we conducted the experiments, we are confident that the $K_{\mathrm{DM}}$ value of $1.5 \times 10^{9} \mathrm{M}^{-1}$ for C120 in $\mathrm{ACN}$ and $K_{\mathrm{DM}}=9 \times 10^{9} \mathrm{M}^{-1}$ in ChB are correct.

The presented absorption chromatograms, particularly that measured for the lowest concentration of C120 in ACN $\left(c_{\mathrm{C} 120}=1.9 \times 10^{-8} \mathrm{M}\right)$, where the monomer peak is unusually small, suggest that obtaining such data is extremely difficult, if possible at all. Therefore, the proposed method for the determination of very high $K_{\mathrm{DM}}$ values, although theoretically correct, is not useful in practice. However, if this method is

Table 9 The effect of $\mathrm{C} 120$ concentration in 1-chlorobutane and excitation and emission wavelengths in a measured emission chromatogram on the emission relative intensity of $\mathrm{DM}, P_{\mathrm{DM}(\text { rel })}$ and $K_{\mathrm{DM}}$ value

\begin{tabular}{|c|c|c|c|c|c|c|}
\hline$c_{\mathrm{C} 120}[\mathrm{M}]$ & $c_{\mathrm{C} 120(\mathrm{rel})}$ & $300 / 380$ & $300 / 400$ & $340 / 420$ & $P_{\mathrm{DM}(\mathrm{rel})}^{\text {avr. }}$ & $K_{\mathrm{DM}}\left(\mathrm{M}^{-1}\right)$ \\
\hline $3.40 \times 10^{-8}$ & 4.99 & 5.19 & 5.35 & 5.30 & 5.28 & $7.5 \times 10^{9 b}$ \\
\hline $6.82 \times 10^{-9}$ & 1.0 & $1.0\left(3.543 \times 10^{5}\right)^{a}$ & $1.0\left(1.987 \times 10^{5}\right)^{a}$ & $1.0\left(1.276 \times 10^{5}\right)^{a}$ & 1.0 & \\
\hline
\end{tabular}

${ }^{a}$ DM peak area is given in parentheses. ${ }^{b}$ See Table S6. 
applied to the determination of $K_{\mathrm{DM}}$ of order $10^{7}-10^{8} \mathrm{M}^{-1}$, then due to significantly lower $K_{\mathrm{DM}}$ value, the monomer concentration will be considerably higher and consequently, the absorbance for the monomer peak will be considerably greater (Tables S7 and S8 $\dagger$ ). As a result, measurements of absorption chromatograms will be easier and error of determined $K_{\mathrm{DM}}$ values will be considerably smaller than those obtained in the case of $K_{\mathrm{DM}} \sim 10^{9} \mathrm{M}^{-1}$, as observed with C120 in ACN. Moreover, when $K_{\mathrm{DM}}=1 \times 10^{7}-1 \times 10^{8} \mathrm{M}^{-1}$, then an ample value of $A_{\mathrm{M}}^{\lambda=300} / A_{\mathrm{DM}}^{\lambda=340}$ ratio is also obtained; as noted with the concentration of $10^{-7} \mathrm{M}$, a relatively large value of $c_{\mathrm{M}} / c_{\mathrm{DM}}$ ratio was obtained. Thus, for the determination of a reliable $K_{\mathrm{DM}}$ it would not be necessary to carry our measurements for concentrations of order of $10^{-8} \mathrm{M}$. For the concentration of $10^{-7} \mathrm{M}$, the measurement error of $A_{\mathrm{M}}^{\lambda=300}$ would be much smaller. Thereby, when $K_{\mathrm{DM}}=10^{7}-10^{8} \mathrm{M}^{-1}$, large values of $\mathrm{S} / \mathrm{N}$ ratio will be obtained from absorption chromatograms not only for DM, but also for M (Tables S7 and S8†).

It is worth noting that conditions for measurements by the UHPLC-PDA-FL method do not perturb the equilibrium between monomer and dimer present in ACN. If such a perturbation occurred, then the determined $K_{\mathrm{DM}}$ would differ from the true $K_{\mathrm{DM}}$ for $\mathrm{C} 120$ solution in $\mathrm{ACN}$ in the concentration range of $1.1 \times 10^{-6}-1.9 \times 10^{-8} \mathrm{M}$. During the chromatographic separation of monomer from dimer an injected C120 sample undergoes a dilution with the eluent. Thereby, during the chromatographic separation, a decrease in the concentration of dimers could occur. If a sample dilution with an eluent or possibly interactions of dimers with the column caused a cleavage of dimers into monomers on the column, then the $K_{\mathrm{DM}}$ determined by the UHPLC-PDA-FL method could be reduced, as compared to the true $K_{\mathrm{DM}}$. This reduction would be greater as the dimer concentration became smaller. The dimer concentration in samples with very different concentrations of $\mathrm{C} 120\left(c_{\mathrm{C} 120}=1.1 \times 10^{-6}-1.9 \times 10^{-8} \mathrm{M}\right)$ and identical all the other measurement conditions (volume of injected sample, eluent flow rate) differed considerably. In the sample with the smallest C120 concentration $c_{\mathrm{C} 120}=1.9 \times 10^{-8} \mathrm{M}$, the dimer concentration was about 5 times lower than in the sample with the concentration of $9.3 \times 10^{-8} \mathrm{M}$ and as much as about 65 times lower than in the sample with the concentration of $1.1 \times 10^{-6} \mathrm{M}$ (Table 5). The same determined value of $K_{\mathrm{DM}}$ (within the margin of error) (Table 3), irrespective of C120 concentration, permitted us to assume that the determined very high $K_{\mathrm{DM}}$ is correct and that the UHPLC-PDA-FL method employed for its determination had no effect on $K_{\mathrm{DM}}$ value.

An independent confirmation comes from the comparison of emission chromatograms measured for C120 in ACN. In studies with the same concentration of $\mathrm{C} 120\left(c_{\mathrm{C} 120}=3 \times 10^{-8} \mathrm{M}\right)$, but with different injection volumes $(v=3,5$ and $10 \mu \mathrm{l}$ ) (Table S9 $\dagger$ ), the corrected peak areas for the dimer in the emission chromatograms were the same when corrected for the effects of volume differences (Fig. S3†). Therefore, irrespective of the extent of sample dilution with the eluent, no cleavage of the dimer into two monomers occurred during the chromatographic process for any of injected samples. Moreover, the same concentration of the dimer, thereby the same $K_{\mathrm{DM}}$ value, was obtained from absorption chromatograms for which dimer retention times differed by a factor of two (Fig. 5a and b and Table 3) due to differences in eluent flow rates. In accordance with the ref. 9 and 10 , the absence of the effect of chromatographic separation conditions on concentrations of monomer and dimer (and consequently on the value of dimerization constant) is the result of very high stability of $\mathrm{C} 120$ dimer in $\operatorname{ACN}\left(E_{\mathrm{DM}} \approx 7000 \mathrm{~cm}^{-1}\right) \cdot{ }^{58}$

Finally we would like to point out the problems encountered while determining very high $K_{\mathrm{DM}}$ values during measurements of absorption and emission chromatograms of C120 in ACN, and particularly in ChB, carried out using a UHPLC-PDA-FL system. We have noticed that the most important and at the same time very difficult experimental problem is the presence of impurities (Imp) in a solvent-eluent. To ensure $\mathrm{M}$ content of at least a few percent in a sample, it is necessary to conduct measurements of a studied compound (SC) at very low concentrations. For instance, if $K_{\mathrm{DM}}=1 \times 10^{9} \mathrm{M}^{-1}$, then $c_{\mathrm{SC}}$ should be of order $10^{-8} \mathrm{M}$. In such conditions, most frequently $c_{\text {Imp }} \gg c_{\mathrm{SC}}$ even in the solvents of the highest purity. If Imp forms hydrogen or coordinate bonds with $\mathrm{M}$ and DM of SC, the fact that $c_{\text {Imp }} \gg c_{\text {SC }}$ causes that instead of DM formation, the

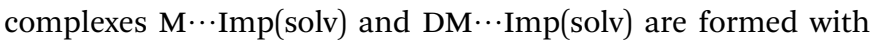
a high yield from $\mathbf{M}$ and DM of a studied compound and impurity molecules. In such cases the determined $K_{\mathrm{DM}}$ values can considerably differ from true $K_{\mathrm{DM}}$ values. It should be emphasized that the above-described problem is not a consequence of the UHPLC-PDA-FL method applied, but to the unavoidable presence of impurities in solvents.

\section{Conclusions}

The most important achievement of this work is a new concept for the application of the UHPLC method with UV-VIS photodiode absorption detector (PDA) and emission detector. It was illustrated by the example of measurements of absorption and emission chromatograms and AS for C120 in ACN and in ChB that a UHPLC-PDA-FL apparatus can be applied to measurements in the range of very low concentrations $\left(10^{-6}-10^{-9} \mathrm{M}\right)$, provided that the detection is carried out with a very sensitive PDA spectrophotometer and emission detector enabling the measurement of both reliable absorption and emission chromatograms and AS, with an error as small as $\Delta A= \pm 2 \times 10^{-5}$ and $\Delta I_{\mathrm{F}}= \pm 1 \times 10^{-2}$. Due to the application of the UHPLC-PDAFL system and core-shell type columns for the separation, one can obtain very narrow $\left(\Delta t_{\mathrm{R}}=1-2 \mathrm{~s}\right.$ in absorption chromatograms and 2-4 $\mathrm{s}$ in emission chromatograms) and clearly separated peaks originating from species formed by the studied compound (and impurities). An important result obtained for C120 in ACN and in ChB was establishing, on the basis of the presence of only two peaks in its absorption and emission chromatograms, that C120 exists only as monomer and dimer species, and not as larger aggregates, within the dye concentration range of $10^{-5}-10^{-9} \mathrm{M}$.

Taking advantage of the unique properties of the UHPLCPDA-FL system, we have proposed in this work a method for the determination of very large homodimerization constant values of $K_{\mathrm{DM}}=10^{6}-10^{10} \mathrm{M}^{-1}$, regardless of the similarity or 
difference between AS of monomer and the dimer. This method enabled us to determine very high values of $K_{\mathrm{DM}}=1.5 \times 10^{9}$ $\mathrm{M}^{-1}$ for $\mathrm{C} 120$ in ACN and $K_{\mathrm{DM}}=9 \times 10^{9} \mathrm{M}^{-1}$ in ChB. The same $K_{\mathrm{DM}}$ value (within the limits of error) determined from emission chromatograms and absorption chromatograms proves that the two procedures for the determination of very large $K_{\mathrm{DM}}$ values are correct.

The $K_{\mathrm{DM}}$ value is especially important in the case of compounds that can easily undergo self-aggregation due to formation of strong hydrogen bonds or coordination bonds as well as due to $\pi-\pi$, dipole-dipole or dispersion interactions, e.g., porphyrins and phthalocyanines, bisimide, merocyanine and squaraine dyes and donor-acceptor compounds. For these compounds, absorption spectra measured using a spectrophotometer usually have very similar shapes in the range of very small concentrations $\left(10^{-5}-10^{-7} \mathrm{M}\right)$. To determine whether a measured AS (as well as ES) comes from M or DM (as is the case for C120) or from both of them, it is necessary to know the $K_{\mathrm{DM}}$ value.

Our demonstration that AS and ES spectra of C120 (which have been published many times ${ }^{48,49}$ ) in each case originated from the dimer, and not from the monomer has a number of important consequences. The values of vertical excitation energy of C120 monomer to the $S_{1}$ state, which has been calculated many times using $a b$ initio and TD-DFT methods, ${ }^{50}$ were always considerably greater (by $3000-5000 \mathrm{~cm}^{-1}$ ) than the experimental values determined using the position of longwavelength band in AS of C120. However, the present study shows that all AS of C120 measured hitherto originated from dimers. The application of the UHPLC-PDA method has enabled us to record AS of the monomer for the first time. Fortunately, the position of the band corresponding to the transition to the $S_{1}$ state of the monomer (Fig. $3 \mathrm{~b}$ ) agreed very well with theoretically calculated values of vertical excitation energy to the $S_{1}$ state of $\mathrm{C} 120$ monomer. ${ }^{50}$

The coexistence of C120 monomer and dimer species, along with their distinct spectral properties (in particular, the location of the long wavelength band in the absorption and emission spectra), opens the possibility to use C120 as a sensitive absorption and fluorescence probe. For example, C120 as a coupled monomer-dimer pair can be used to control the release of the $\mathrm{C} 120$ monomer species from $\mathrm{N}$-linked oligosaccharides and the formation of the C120 dimer species. ${ }^{69}$

For a number of compounds, very high energies of dimerization have been calculated, $E_{\mathrm{DM}}>5000 \mathrm{~cm}^{-1,1-3,57,70}$ sometimes for more than one dimer structure. ${ }^{1,57,70}$ For such compounds, the value of $K_{\mathrm{DM}}$ would be very high. It would be interesting to use the proposed UHPLC-PDA method to determine these values.

\section{Conflicts of interest}

There are no conflicts to declare.

\section{Abbreviations}

ES

$K_{\mathrm{DM}}$

A, B

$K_{\text {eq }}$

$K_{\text {ass }}$

$c_{\mathrm{M}}$

$c_{\mathrm{DM}}$

$\mathrm{M}$

$\mathrm{DM}$

$\varepsilon(\lambda)$

$\Phi_{\mathrm{E}}$

$\Phi_{\mathrm{F}}$

$\lambda_{\mathrm{em}}$

$\lambda_{\mathrm{ex}}$

$\varepsilon^{\max }$

UHPLC

HPLC

UHPLC-

PDA-FL

$t_{\mathrm{R}}$

$\Delta t_{\mathrm{R}}{ }^{1 / 2}$

A

$\Delta A$

$t_{\mathrm{R}}^{\max }$

ACN

ChB

$\mathrm{S} / \mathrm{N}$

$\varepsilon_{\mathbf{M}}^{\max }$

$\varepsilon_{\mathrm{DM}}^{\max }$

$c_{\mathrm{C} 120}$

$c_{\mathrm{C} 120(\mathrm{rel})}$

$A_{\mathrm{M}}^{\lambda=300}$

$A_{\mathrm{DM}}^{\lambda=340}$

$c_{\mathrm{M}(\mathrm{rel})}$

$c_{\mathrm{DM}(\mathrm{rel})}$

$\varepsilon_{\mathrm{M}}^{300}$

$\varepsilon_{\mathrm{DM}}^{340}$

$A_{\mathrm{M}(\mathrm{rel})}^{\lambda=300}$

M(rel)

$A_{\mathrm{DM}(\mathrm{rel})}^{\lambda=340}$

$\lambda^{\max }$

$\alpha$

$P_{\mathrm{M}}$

$P_{\mathrm{DM}}$

$P_{\mathrm{DM}}^{340}$

$P_{\mathrm{M}}^{300}$

$P_{\mathrm{M}(\mathrm{rel})}$

$P_{\mathrm{DM}(\mathrm{rel})}$

$P_{\mathrm{DM}(\text { rel })}{ }^{\text {avr }}$ $K_{\mathrm{DM}}^{300}$

$K_{\mathrm{DM}}^{310}$

$E_{\mathrm{DM}}$
Emission spectra

Homo-dimerization constant (dimerization constant)

Different chemical compounds

Equilibrium constant

Association constant

Monomer concentration

Dimer concentration

Monomer

Dimer

Molar absorption coefficient

Quantum yield of emission

Quantum yield of fluorescence

Emission wavelength

Excitation wavelength

Molar absorption coefficient at the maximum Ultra-high performance liquid chromatography

High performance liquid chromatography

Ultra-high performance liquid chromatography apparatus in conjunction with a photodiode UVVIS spectrophotometer and an emission detector Retention time

Peak width at half maximum of intensity Absorbance

Error of the absorbance measurement

Retention time at the maximum

Acetonitrile

1-Chlorobutane

Signal/noise ratio

Molar absorption coefficient of the monomer at the maximum

Molar absorption coefficient of the dimer at the maximum

Concentration of $\mathrm{C} 120$

Relative concentration of $\mathrm{C} 120$

Absorbance of monomer at $\lambda=300 \mathrm{~nm}$

Absorbance of dimer at $\lambda=340 \mathrm{~nm}$

Relative concentration of monomer

Relative concentration of dimer

Molar absorption coefficient of monomer at 300

$\mathrm{nm}$

Molar absorption coefficient of dimer at $340 \mathrm{~nm}$ (at the maximum)

Relative absorbance of monomer at $\lambda=300 \mathrm{~nm}$ Relative absorbance of dimer at $\lambda=340 \mathrm{~nm}$

Wavelength at the maximum

Mole fraction of the monomer species

Area of dimer peak

Area of monomer peak

Area of dimer peak at $\lambda=340 \mathrm{~nm}$

Area of monomer peak $\lambda=300 \mathrm{~nm}$

Relative area of monomer peak

Relative area of dimer peak

Average value of relative area of dimer peak

Dimerization constant, where $P_{\mathrm{M}}$ was measured at $\lambda=300 \mathrm{~nm}$

Dimerization constant, where $P_{\mathbf{M}}$ was measured at $\lambda=310 \mathrm{~nm}$

Dimerization energy 


$\begin{array}{ll}\varepsilon_{\mathrm{TM}}^{\max } & \begin{array}{l}\text { Molar absorption coefficient of trimer at the } \\ \text { maximum }\end{array} \\ K_{\mathrm{TM}} & \begin{array}{l}\text { Trimerization constant } \\ c_{\mathrm{TM}}\end{array} \\ \end{array}$

\section{Acknowledgements}

We thank Julia Józkowiak, MSc, for the technical support. The authors are very grateful to Professors Ryszard Fiedorow and Jacek Kubicki for help in manuscript preparation. A part of chromatographic measurements were performed at the Centre for Ultrafast Laser Spectroscopy at the A. Mickiewicz University in Poznań, Poland.

\section{References}

1 (a) P. Osswald and F. Würthner, J. Am. Chem. Soc., 2007, 129, 14319-14326; (b) Z. Xie and F. Würthner, Org. Lett., 2010, 12, 3204-3207; (c) U. Mayerhöffer and F. Würthner, Chem. Sci., 2012, 3, 1215-1220; (d) M. M. Safont-Sempere, G. Fernández and F. Würthner, Chem. Rev., 2011, 111, 5784-5814; (e) Z. Chen, A. Lohr, C. R. Saha-Möller and F. Würthner, Chem. Soc. Rev., 2009, 38, 564-584.

2 (a) S. H. M. Söntjens, R. P. Sijbesma, M. H. P. van Genderen and E. W. Meijer, J. Am. Chem. Soc., 2000, 122, 7487-7493; (b) F. H. Beijer, R. P. Sijbesma, H. Kooijman, A. L. Spek and E. W. Meijer, J. Am. Chem. Soc., 1998, 120, 6761-6769; (c) J. H. K. Ky Hirschberg, F. H. Beijer, H. A. van Aert, P. C. M. M. Magusin, R. P. Sijbesma and E. W. Meijer, Macromolecules, 1999, 32, 2696-2705; (d) T. F. A. de Greef, M. M. L. Nieuwenhuizen, P. J. M. Stals, C. F. C. Fitie, A. R. A. Palmans, R. P. Sijbesma and E. W. Meijer, Chem. Commun., 2008, 4306-4308; (e) T. F. A. de Greef, M. M. J. Smulders, M. Wolffs, A. P. H. J. Schenning, R. P. Sijbesma and E. W. Meijer, Chem. Rev., 2009, 109, 5687-5754.

3 (a) P. S. Corbin and S. C. Zimmerman, J. Am. Chem. Soc., 1998, 120, 9710-9711; (b) D. W. Kuykendall, C. A. Anderson and S. Zimmerman, Org. Lett., 2009, 11, 61-64; (c) E. M. Todd, J. R. Qinn, T. Park and S. C. Zimmerman, Isr. J. Chem., 2005, 45, 381-389.

4 (a) C. A. Hunter, Angew. Chem., Int. Ed., 2004, 43, 5310-5324;

(b) B. A. Blight, C. A. Hunter, D. A. Leigh, H. McNab and P. I. T. Thomson, Nat. Chem., 2011, 3, 244-248; (c) C. A. Hunter and L. D. Sarson, Angew. Chem., Int. Ed. Engl., 1994, 33, 2313-2316.

5 (a) D. A. Leigh, C. C. Robertson, A. M. Z. Slawin and P. I. T. Thomson, J. Am. Chem. Soc., 2013, 135, 9939-9943; (b) S. Djurdjevic, D. A. Leigh, H. McNab, S. Parsons, G. Teobaldi and F. Zerbetto, J. Am. Chem. Soc., 2007, 129, 476-477.

6 (a) A. Satake and Y. Kobuke, Tetrahedron, 2005, 61, 13-41; (b) Y. Kobuke and H. Miyaji, J. Am. Chem. Soc., 1994, 116, 41114112.

7 S. Schlund, C. Schmuck and B. Engels, J. Am. Chem. Soc., 2005, 127, 11115-11124.
8 C. Maeda, T. Kamada, N. Aratani, T. Sasamori, N. Tokitoh and A. Osuka, Chem.-Eur. J., 2009, 15, 9681-9684.

9 A. Shao, Z. Guo, S. Zhu, P. Tian, H. Shi and W. Zhu, Chem. Sci., 2014, 5, 1383-1389.

10 S. Gadde, E. K. Batchelor, J. P. Weiss, Y. Ling and A. E. Kaifel, J. Am. Chem. Soc., 2008, 130, 17114-17119.

11 P. Thordarson, Chem. Soc. Rev., 2011, 40, 1305-1323.

12 M. Kubista, R. Sjöback and B. Albinsson, Anal. Chem., 1993, 65, 994-998.

13 R. P. Sijbesma, F. H. Beijer, L. Brunsveld, B. J. B. Folmer, J. H. K. Ky Hirschberg, R. F. M. Lange, J. K. L. Lowe and E. W. Meijer, Science, 1997, 278, 1601-1604.

14 (a) G. B. W. L. Ligthart, H. Ohkawa, R. P. Sijbesma and E. W. Meijer, J. Am. Chem. Soc., 2005, 127, 810-811; (b) T. F. A. de Greef, M. M. L. Nieuwenhuizen, R. P. Sijbesma and E. W. Meijer, J. Org. Chem., 2010, 75, 598-610.

15 M. Mizumura, H. Shinokubo and A. Osuka, Angew. Chem., Int. Ed., 2008, 47, 5378-5381.

16 (a) M. M. Safont-Sempere, P. Ossswald, K. Radacki and F. Würthner, Chem.-Eur. J., 2010, 16, 7380-7384; (b) S. Ghosh, X.-Q. Li, V. Stepanenko and F. Würthner, Chem.Eur. J., 2008, 14, 11343-11357.

17 (a) S. Liu, C. Ruspic, P. Mukhopadhyay, S. Chakrabarti, P. Y. Zavalij and L. Isaacs, J. Am. Chem. Soc., 2005, 127, 15959-15967; (b) A. Wu and L. Isaacs, J. Am. Chem. Soc., 2003, 125, 4831-4835.

18 Z. Chen, U. Baumeister, C. Tschierske and F. Würthner, Chem.-Eur. J., 2007, 13, 450-465.

19 (a) F. C. Spano, J. Am. Chem. Soc., 2009, 131, 4267-4278; (b) F. C. Spano, S. C. J. Meskers, E. Hennebicq and D. Beljonne, J. Chem. Phys., 2008, 129, 024704.

20 L. Brusveld, B. J. B. Folmer, E. W. Meijer and R. P. Sijbesma, Chem. Rev., 2001, 101, 4071-4097.

21 B. J. B. Folmer, R. P. Sijbesma, R. M. Versteegen, J. A. J. van der Rijt and E. W. Meijer, Adv. Mater., 2000, 12, 874-878.

22 (a) Y. Kang and M. E. Meyerhoff, Anal. Chim. Acta, 2006, 565, 1-9; (b) Y. Kang, J. W. Kampf and M. E. Meyerhoff, Anal. Chim. Acta, 2007, 598, 295-303.

23 Y. Xu, Z. Li, A. Malkovskiy, S. Sun and Y. Pang, J. Phys. Chem. $B, 2010,114,8574-8580$.

24 S. Chen, et al., Chem. Sci., 2012, 3, 1804-1809.

25 H.-M. Zhang, X.-Q. Guo, Y.-B. Zhao, D.-Y. Wang and J.-G. Xu, Anal. Chim. Acta, 1998, 361, 9-17.

26 T. F. A. de Greef, G. Ercolani, G. B. W. L. Ligthart, E. W. Meijer and R. P. Sijbesma, J. Am. Chem. Soc., 2008, 130, 13755-13764.

27 X.-Z. Wang, X.-Q. Li, X.-B. Shao, X. Zhao, P. Deng, X.-K. Jiang, Z.-T. Li and Y.-Q. Chen, Chem.-Eur. J., 2003, 9, 2904-2913.

28 F. Bergström, I. Mikhalyov, P. Hägglöf, R. Wortmann, T. Ny and L. B.-Å. Johansson, J. Am. Chem. Soc., 2002, 124, 196-204.

29 K. A. Kistler, C. M. Pochas, H. Yamagata, S. Matsika and F. C. Spano, J. Phys. Chem. B, 2012, 116, 77-86.

30 T. Kamada, N. Aratani, T. Ikeda, N. Shibata, Y. Higuchi, A. Wakamiya, S. Yamaguchi, K. Suk Kim, Z. Yoon, D. Kim and A. Osuka, J. Am. Chem. Soc., 2006, 128, 7670-7678.

31 A. Niazi, A. Yazdanipour, J. Ghasemi and M. Kubista, Spectrochim. Acta, Part A, 2006, 65, 73-78. 
32 S. Nagao, H. Ishikawa, T. Yamada, Y. Mizutani and S. Hirota, J. Biol. Inorg Chem., 2015, 20, 523-530.

33 G. Ercolani, Chem. Commun., 2001, 1416-1417.

34 (a) B. Ciesielska, A. Łukaszewicz, L. Celewicz, A. Maciejewski and J. Kubicki, Appl. Spectrosc., 2007, 61, 102-109; (b) B. Ciesielska, J. Kubicki, A. Maciejewski and S. Paszyc, Chem. Phys. Lett., 2002, 353, 69-76.

35 E. Krystkowiak, R. A. Bachorz and A. Maciejewski, Phys. Chem. Chem. Phys., 2016, 18, 492-502.

36 (a) L. Braco, C. Bano, F. Chillaron and C. Abad, J. Biol. Macromol., 1988, 10, 343-348; (b) D. Salom, M. C. Bañó, L. Braco and C. Abad, Anal. Chim. Acta, 1997, 352, 309-317.

37 (a) F. Zeng, S. C. Zimmerman, S. V. Kolotuchin, D. E. C. Reichert and Y. Ma, Tetrahedron, 2002, 58, 825843; (b) J. Yang, E. Fan, S. J. Geib and A. D. Hamilton, J. Am. Chem. Soc., 1993, 115, 5314-5315.

38 (a) R. A. Haycock, C. A. Hunter, D. A. James, U. Michelsen and L. R. Sutton, Org. Lett., 2000, 2, 2435-2438; (b) G. M. Whitesides, E. E. Simanek, J. P. Mathias, C. T. Seto, D. N. Chin, M. Mammen and D. M. Gordon, Acc. Chem. Res., 1995, 28, 37-44; (c) K. J. Lampi, J. T. Oxford, H. P. Bachinger, T. R. Shearer, L. L. David and D. Kapfer, Exp. Eye Res., 2001, 72, 279-288.

39 (a) H. Ye, Anal. Biochem., 2006, 356, 76-85; (b) M. D. Bond, M. E. Panek, Z. Zhang, D. Wang, P. Mehndiratta, H. Zhao, K. Gunton, A. Ni, M. L. Nedved, S. Burman and D. B. Volkin, J. Pharm. Sci., 2010, 99, 2582-2597; (c) K. Ahrer, A. Buchacher, G. Iberer, D. Josic and A. Jungbauer, J. Chromatogr. A, 2003, 1009, 89-96; (d) G. B. Irvine, Anal. Chim. Acta, 1997, 352, 387-397.

40 (a) N. Gutowska and A. Maciejewski, RSC Adv., 2014, 4, 31775-31781; (b) N. Gutowska and A. Maciejewski, J. Photochem. Photobiol., A, 2016, 29, 1-8.

41 N. Nandi, K. Bhattacharyya and B. Bagchi, Chem. Rev., 2000, 100, 2013-2046.

42 B. D. Wagner, Molecules, 2009, 14, 210-237.

43 S. George, M. Kumbhakar, P. K. Singh, R. Ganguly, S. Nath and H. Pal, J. Phys. Chem. B, 2009, 113, 5117-5127.

44 M. Grazula and E. Budzisz, Coord. Chem. Rev., 2009, 253, 2588-2598.

45 M. Y. Berezin and S. Achilefu, Chem. Rev., 2010, 110, 26412684.

46 M. V. Kulkarni, G. M. Kulkarni, C.-H. Lin and C.-M. Sun, Curr. Med. Chem., 2006, 13, 2795-2818.

47 S. S. Anufrik and V. V. Tarkovsky, J. Appl. Spectrosc., 2010, 77, 640-647.

48 H. Pal, S. Nad and M. Kumbhakar, J. Chem. Phys., 2003, 119, 443-452.
49 K. Rechthaler and G. Kohler, Chem. Phys., 1994, 189, 99-116. 50 (a) W. Zhao, L. Pan, W. Bian and J. Wang, ChemPhysChem, 2008, 9, 1593-1602; (b) P. Zhou, P. Song, J. Liu, K. Han and G. He, Phys. Chem. Chem. Phys., 2009, 11, 9440-9449; (c) T. Sakata, Y. Kawashima and H. Nakano, J. Phys. Chem. A, 2010, 114, 12363-12368; (d) R. J. Cave, K. Burke and E. W. Castner, J. Phys. Chem. A, 2002, 106, 9294-9305.

51 M.-G. Choi, E. Lee, H.-S. Chung, S.-H. Jang and C. W. Lee, BMB Rep., 2011, 44, 458-461.

52 M. Yodoshi, A. Tani, Y. Ohta and S. Suzuki, J. Chromatogr. A, 2008, 1203, 137-145.

53 R. Tandon, et al., J. Antimicrob. Chemother., 2011, 66, 25432555.

54 X. Liu, M. Dong, X. Chen, M. Jiang, X. Lv and J. Zhou, Appl. Microbiol. Biotechnol., 2008, 78, 241-247.

55 (a) X. Liu, J. M. Cole and K. S. Low, J. Phys. Chem. C, 2013, 117, 14723-14730; (b) X. Liu, J. M. Cole, P. C. Y. Cow, L. Zhang, Y. Tan and T. Zhao, J. Phys. Chem. C, 2014, 118, 13042-13051.

56 (a) P. Verma and H. Pal, J. Phys. Chem. A, 2012, 116, 44734484; (b) P. Verma and H. Pal, J. Phys. Chem. A, 2014, 118, 6950-6964.

57 (a) M. Cigan, J. Donovalova, V. Szöcs, J. Gaspar, K. Jakusowa and A. Gaplovsky, J. Phys. Chem. A, 2013, 117, 4870-4883; (b) A. Stamm, K. Schwing and M. Gerdhardsm, J. Chem. Phys., 2014, 141, 194304.

$58 \mathrm{~J}$. Koput, M. Hetmańska and A. Maciejewski, to be published.

59 J. Kozłowski, A. Maciejewski, M. Milewski and W. Urjasz, J. Phys. Org. Chem., 1992, 12, 47-52.

60 (a) M. Kasha, H. R. Rawls and M. A. El-Bayoumi, Pure Appl. Chem., 1965, 11, 371-392; (b) E. G. McRae and M. Kasha, J. Chem. Phys., 1958, 28, 721-722; (c) A. S. Davydov, Phys.Usp., 1964, 7, 145-178.

61 J. C. Dearden, Can. J. Chem., 1963, 41, 2683-2691.

62 M. Ito, J. Mol. Spectrosc., 1960, 4, 125-143.

63 F. Gritti and G. Guiochon, J. Chromatogr. A, 2004, 1028, 197210.

64 S. Levin and E. Grushka, Anal. Chem., 1986, 58, 1602-1607. 65 D. V. McCalley, Anal. Chem., 2003, 75, 3404-3410.

66 J. Srbek, P. Coufal, Z. Bosáková and E. Tesařová, J. Sep. Sci., 2005, 28, 1263-1270.

67 S. Williams, J. Chromatogr. A, 2004, 1052, 1-11.

68 S. Levin and E. Grushka, Anal. Chem., 1987, 59, 1157-1164.

69 M. Yodoshi, A. Tani, Y. Ohta and S. Suzuki, J. Chromatogr. A, 2008, 1203, 137-145.

70 M. Bayda, F. Dumoulin, G. L. Hug, J. Koput, R. Gorniak and A. Wójcik, Dalton Trans., 2017, 46, 1914-1926. 